\title{
Parameter Optimization of Gas Metal Arc Welding Process on AISI: 430 Stainless Steel Using Meta Heuristic Optimization Techniques
}

\section{P. Ravichandran}

Kongu Engineering College

Meenakshipriya B ( $\sim$ bmp@kongu.ac.in )

Kongu Engineering College https://orcid.org/0000-0001-9586-5696

\section{R. Parameshwaran}

Kongu Engineering College

C. Maheswari

Kongu Engineering College

\section{E.B. Priyanka}

Kongu Engineering College

P. Sivapathasekaran

Kongu Engineering College

\section{Original Article}

Keywords: GMAW Process, AISI: 430 Stainless Steel, IRB 1410 Industrial Manipulator, RSM Methodology, Meta Heuristic Optimization Techniques

Posted Date: August 21st, 2020

DOl: https://doi.org/10.21203/rs.3.rs-53362/v1

License: (9) This work is licensed under a Creative Commons Attribution 4.0 International License. Read Full License 


\title{
Parameter Optimization of Gas Metal Arc Welding Process on AISI: 430 Stainless Steel using Meta Heuristic Optimization Techniques
}

\author{
P. Ravichandran ${ }^{1}$, B. Meenakshipriya ${ }^{1}$ (Corresponding Author), R. Parameshwaran ${ }^{1}$, C. Maheswari ${ }^{1}$, E.B. Priyanka ${ }^{1}$, \\ P. Sivapathasekaran ${ }^{1}$ \\ ${ }^{1}$ Department of Mechatronics Engineering, Kongu Engineering College, Perundurai, India-638060. \\ Email id: bmp@kongu.ac.in
}

\begin{abstract}
The superiority and profile of the weld obtained through Gas Metal Arc Welding (GMAW) are not only depends on the chemical configuration of the flux, but also on the choice of welding parameters. Since variety of process parameters influence the results, a proper empathetic of process performance and identification of suitable welding conditions (i.e. optimum setting of process parameters) are indeed essential to enhance quality. The present work highlights the application and comparison of single-response optimization using Response Surface Methodology (RSM) with Meta Heuristic Optimization techniques namely Particle Swarm Optimization (PSO) and Firefly Algorithm (FA). The experimental analysis is conducted by optimizing the input parameters like Current Rating (Amp), Feed Rate (m/min), Welding Speed $(\mathrm{mm} / \mathrm{sec})$ and Gas Flow $(1 / \mathrm{m})$. An attempt has been made in the present research work by taking AISI: 430 stainless steel specimens to compare and analyse the performance in terms of weld bead geometry (Bead Width (mm), Bead Height ( $\mathrm{mm}$ ) and Depth of Penetration (mm)), Hardness (VHN) and Tensile Strength $\left(\mathrm{N} / \mathrm{mm}^{2}\right)$ using IRB 1410 Industrial manipulator. The effect of process parameters on ferritic stainless steel of series 400 (AISI: 430) grade has been analysed using Response Surface Methodology (RSM) method. Further, Meta Heuristic Optimization techniques namely Particle Swarm Optimization (PSO) and Firefly Algorithm (FA) have been developed further to minimize the bead width, bead height and maximize the depth of penetration. While fairly similar results were achieved with the implementation of Particle Swarm Optimization (PSO) and Firefly Algorithm (FA) were computationally efficient. Experimental validation of the single-objective as well as multi-objective optimization results indicates that the empirical models for the quality prediction with proposed optimization results are better for the GMAW process by IRB 1410 Industrial manipulator.
\end{abstract}

Key Words: GMAW Process, AISI: 430 Stainless Steel, IRB 1410 Industrial Manipulator, RSM Methodology, Meta Heuristic Optimization Techniques

\section{INTRODUCTION}

Nowadays, a non hardenable AISI: 430 Stainless Steel which belongs to ferritic group of steels is widely developed for its good resistance and formability, and also for its good mechanical properties. Highly stress corrosion resistance and relatively low production cost are the main reasons for the increasing applications of AISI 430 ferritic stainless steels [1]. AISI: 430 stainless steels are essentially used in automotive systems, structural frames, body paneling of buses and coaches, and home appliances [2]. Among the other welding process GMAW is a versatile process extensively used in manufacturing of ferrous and non-ferrous materials as it greatly improves the weldment quality characteristics. Gas Metal Arc Welding (GMAW) is an arc welding process in which the heat source is an arc formed between the consumable metal electrode and the work piece with an external supplied inert gas such as argon or helium [3].

The production of high quality weld joint is mainly depends on the features of the bead geometry, mechanical metallurgical characteristics of the weld as on the various aspects of weld chemistry, and these features are highly influenced by the variables such as Weld Bead Geometry (Bead Height (BH), Depth of Penetration (DOP) and Bead Width (BW)), Hardness (HD) test and Tensile (TS) test and the different input parameters such as Welding Current, Feed Rate, Welding Speed and Gas Flow [4-9]. The international engineering and welding communities like European Federation for Welding, Joining and Cutting (EWF) is strongly interested in investing in research and development geared towards finding optimized methods for obtaining weldments of acceptable quality [10]. Numerous expert methods such as artificial neural network, fuzzy logic, finite element, genetic algorithm etc. have been applied for optimizing process parameters, since it has been found that applying the most appropriate process parameters has a huge impact on the eventual quality of each weldment [11-15]. 
In order to assure the quality of the weldments, welding parameters are preferably optimized using conventional optimization technique like Response Surface Methodology (RSM) and Taguchi Method. Compare with Taguchi, RSM is wished for achieving the desired quality and process optimization [16] because it will be used to determine the cause and effect relationship between true mean response and input control variables for the selection of optimum process parameters. In recent days, various Meta heuristic algorithm like PSO (Particle Swarm Optimization), GA (Genetic Algorithm), ANN (Artificial Neural Network) and BPNN (Back Propagation Neural Network) have also been applied to find desired process parameters. Currently robotic welding systems are becoming increasingly popular and tend to substitute more and more mechanized and automated welding [17-25]. Robotic welding equipment can be programmed for different weldments. In this paper an attempt has been directed towards the development of a Meta Heuristic Optimization Techniques to optimize the welding parameters for the material Ferritic Stainless Steel 430 using IRB 1410 Arc Welding Robot.

\section{MATERIALS AND METHODS}

\subsection{EXPERIMENTAL DESIGN}

In the present work, IRB 1410 Arc Welding Robot is utilised to perform the experimental investigations. The experimental Setup of IRB 1410 Arc Welding Robot is shown in Figure 1 and its specification are given in Table 1. This industrial manipulator is designed to offer the high-quality welds with minimum downtime and provides operators with intelligent controls to manage the welding process parameters. The new intelligent welding power source (special type of electrical power is required to make an arc welding) provides the enhanced control of welding process, allowing the operators to specify the process parameters such as voltage, current and gas flow. During the arc welding process, an arc welding gun or torch is used to transmit current from welding cable to electrode. If the nozzle of the torch become close to the arc, spatter will be gradually deposited on the specimen. To avoid that, a torch cleaner is often used in the process to remove the spatters. Wire feeder is also used to feed the consumable electrode during the arc welding process to ensure the continuous flow. Wire feeder coil is fixed with the guide tube over the roller as shown in the figure. At the end of the torch, wire liner should be visible to confirm the wire feeder coil is aligned accurately with the guide tube. Nozzle hole of $0.8 \mathrm{~mm}$ meter is adapted in the torch end and pushed the wire liner manually for a few lengths to start the feeding. If any hit occurred on the wire liner, there may be misalignment with the wire liner. The wire feeder coil is driven by friction between the wire feed drive roller and the wire.

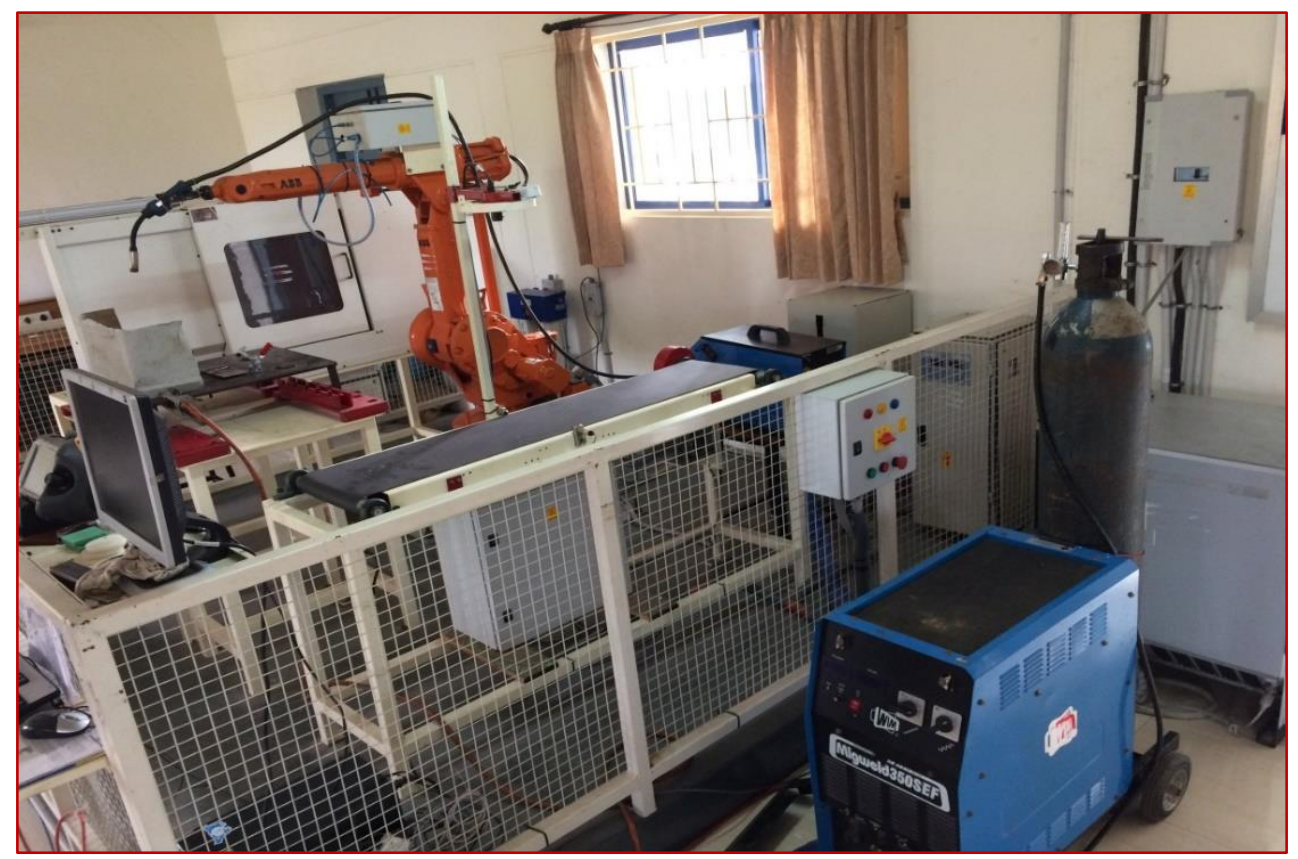

Figure 1. IRB 1410Arc Welding Robot

Table 1. IRB 1410 Arc Welding Robot specifications 


\begin{tabular}{|c|c|}
\hline Parameters & Value \\
\hline Handling Capacity & $5 \mathrm{~kg}$ \\
\hline Number of axes & 6 \\
\hline Accuracy & $0.05 \mathrm{~mm}$ \\
\hline Weight & $225 \mathrm{~kg}$ \\
\hline Wire Feeder Diameter & $1.2 \mathrm{~mm}$ \\
\hline
\end{tabular}

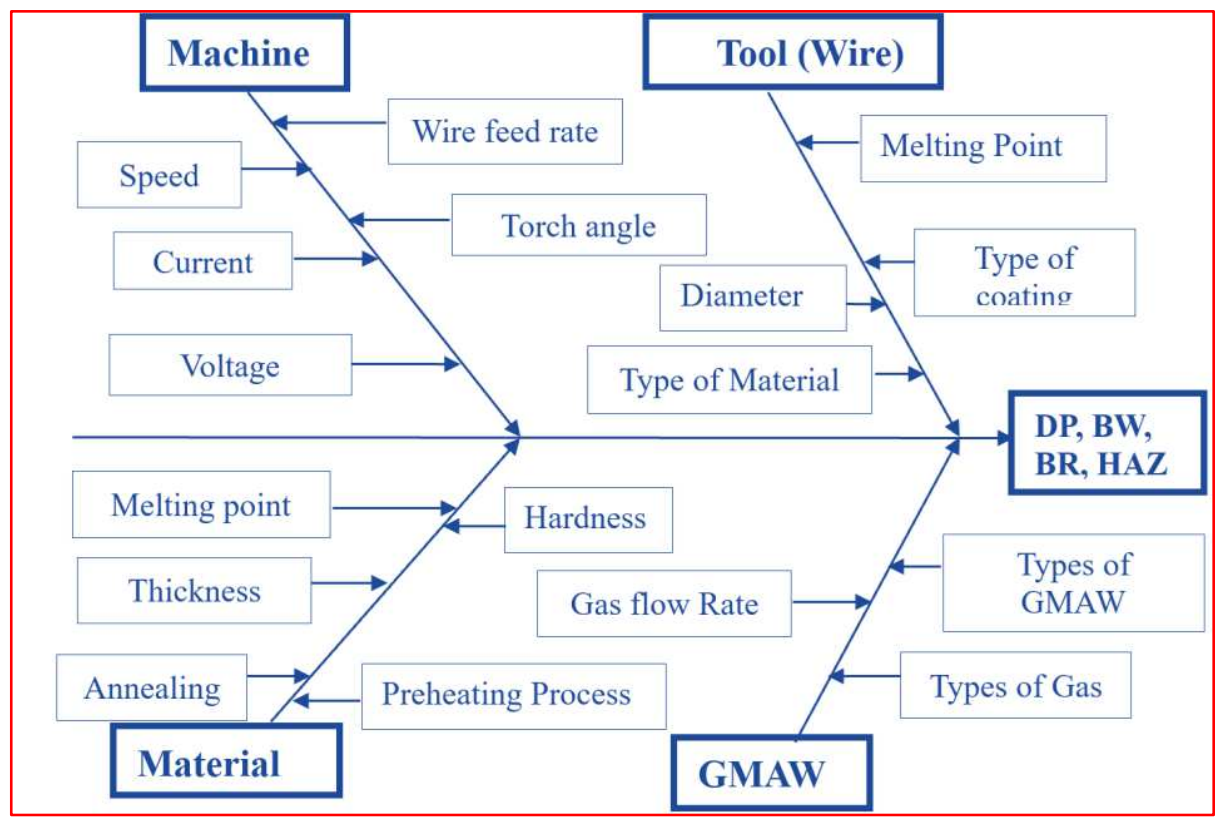

Figure 2. Cause and effect schematic of GMAW process

Cause and effect analysis technique is implemented to identify the most probable causes affecting a welding process. It can help to analyze cause and effect relationships associated with input and output parameters for better performance and accuracy. It visually depicts a clear picture of the possible causes of a particular parameter impact on the output responses. The welding effect is placed in a box on the right and a long process line in drawn pointing to the box as shown in Figure 2. Usually the major categories of welding causes are implying that it relies mainly on the Machine (Equipment), Method and Material. Each of these welding causes can be viewed as an affect in its own right with its own process. Based on the inferences, the following fixture design, base material and gas selections are carried out to optimize the process with better accuracy.

\subsection{FIXTURE DESIGN}

A fixture is a supportive element essentially required in most of the automation manufacturing systems, inspections, and assembly operations. Fixture supports to securely locate the workpiece in a required position or orientation with respect to any component like cutting tool or measuring device as for instance in assembly or welding. The robotic welding operation requires specialized fixtures to accurately hold the weld piece during welding operation. The fixture is fabricated for the size $600 \mathrm{~mm} \times 600 \mathrm{~mm} \times 20 \mathrm{~mm}$ to provide a supporting structure with greater capabilities to hold the workpieces. Toggle clamps are also used to clamp the workpiece in the fixture as shown in the Figure 3. 


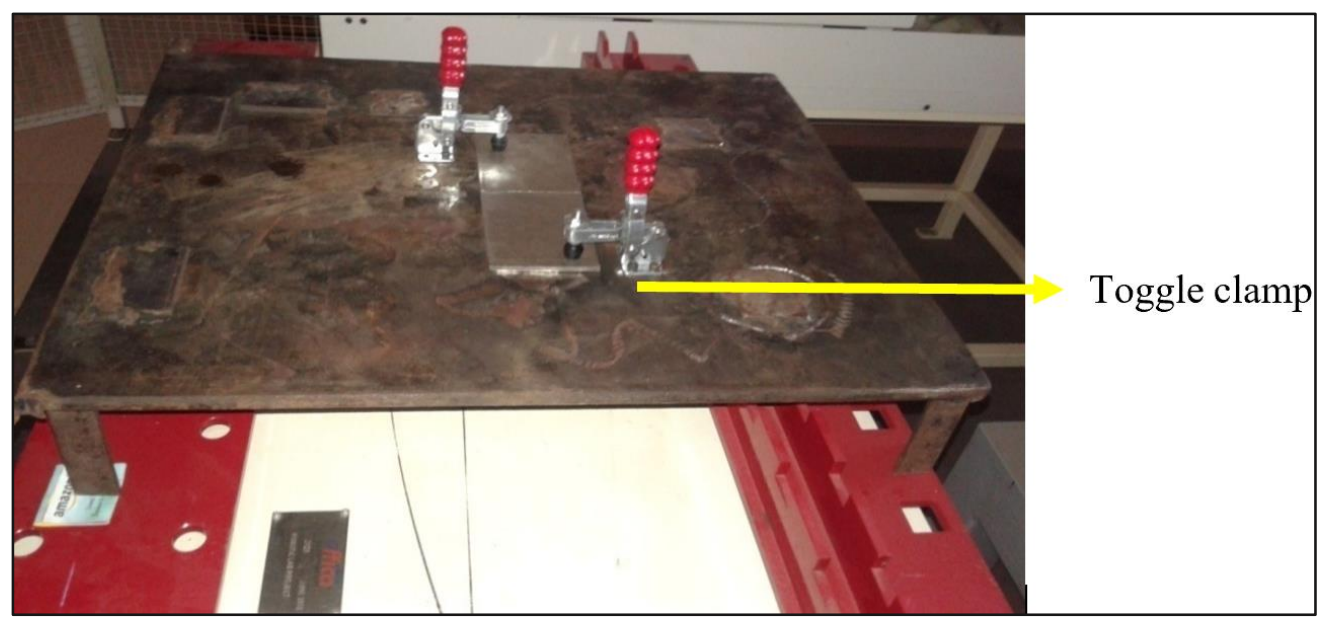

Figure 3. Fixture design taken for the present work

Toggle clamps used in this fixture helps to hold the workpiece in the immobility state. The clamps are operated manually through a lever system. If the lever actuated, the clamp moves against the work piece and holds the specimen rigidly. Toggle clamps will firmly hold the work piece until the operator move the lever to release the toggle. In between the work piece and fixture, rubber wiper is placed which acts as securing element.

\subsection{BASE MATERIAL SELECTION}

The material AISI: 430 is a non-hardenable steel contains 16 to $18 \%$ straight chromium and belongs to the ferritic group of steels. This material is well known for its good corrosion resistance and formability coupled with better mechanical properties. Ferritic stainless steel is magnetic and better resistance to high temperature corrosion than the martensitic types. This material is widely used in functional applications where the cost is major factor e.g. automotive exhaust systems, catalytic convertor, radiator caps, and chimney liners. This steel is routinely joined by all fusion and resistance welding processes with the consideration of two important factors of weld joints such as solidification cracking and preservation of corrosion resistance in the heat affected zone. The chemical composition of the base material and the filler wire are given in Table 2 and Table 3. The chemical composition is measured by Optical Emission Spectrometer (BRIRD- DV6). The test plate dimensions are $100 \mathrm{~mm}$ x $83 \mathrm{~mm}$ x $5.8 \mathrm{~mm}$. The electrode used is 430 flux core wire (CF- 8C) with the diameter of $0.8 \mathrm{~mm}$.

Table 2 Chemical composition of base material

\begin{tabular}{|c|c|c|c|c|c|c|}
\hline Material & $\mathrm{C}$ & $\mathrm{Mn}$ & $\mathrm{P}$ & $\mathrm{S}$ & $\mathrm{Si}$ & $\mathrm{Cr}$ \\
\hline AISI 430 & 0.019 & 0.383 & 0.026 & 0.003 & 0.470 & $16-18$ \\
\hline
\end{tabular}

Table 3 Chemical composition of wire feed coil

\begin{tabular}{|c|c|c|c|c|c|c|}
\hline Material & $\mathrm{C}$ & $\mathrm{Mn}$ & $\mathrm{P}$ & $\mathrm{S}$ & $\mathrm{Si}$ & $\mathrm{Cr}$ \\
\hline AISI 430 & 0.019 & 0.383 & 0.026 & 0.003 & 0.470 & $16-18$ \\
\hline
\end{tabular}

\subsection{Gas Selection}

The general gases used for MIG welding process are Argon, Carbon dioxide $\left(\mathrm{CO}_{2}\right)$, Oxygen $\left(\mathrm{O}_{2}\right)$ and Helium. The most commonly used mixtures of gases for stainless steel are $2 \%$ Carbon dioxide and $98 \%$ Argon to protect the weld part from atmosphere gases and water vapour. Argon gases supports to ensure the quality of the weld compare to the other gases. Argon gas flow can be controlled by flow regulator in the Argon cylinder. In this experimentation, torch maintains the wire feeder and gas flow will be in stable condition during welding operation. The diameter of the welding wire depends upon the base material thickness. According to the base material thickness as $5.8 \mathrm{~mm}$, the wire feeder wire is selected as $0.8 \mathrm{~mm}$ throughout the welding operation. 


\section{EXPERIMENTATION DESIGN AND PROCEDURE}

In all the welding processes, the quality of welded joints greatly influenced by the values of process parameters. Moreover, joint edge preparation has often necessary when plates with more than $5 \mathrm{~mm}$ thickness. This edge modification concentrates due to the heat in melted area and reduces the arc power which was necessary for penetration. This result in lowering the heat input rate and reduces the risk of unforeseen distortions or metallurgical structure alterations. The joint edge geometry will be specified by groove angle, root face and root opening as shown in Figure 4.

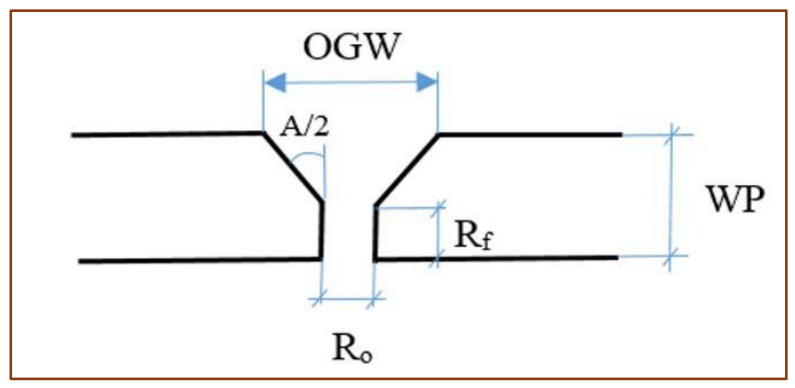

Figure 4. Joint edge specifications for GMAW of plates

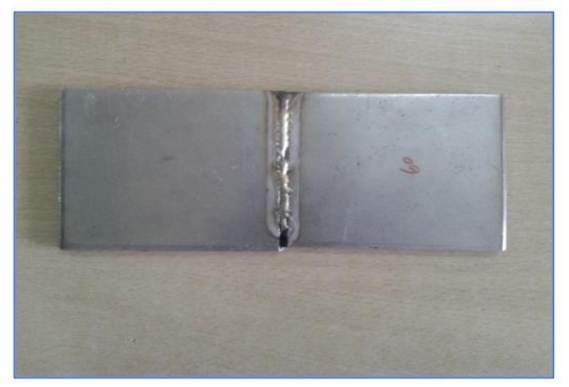

$60^{\circ}$ Groove Angle without gap

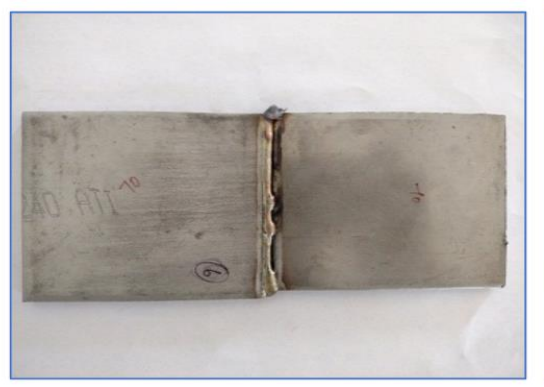

$60^{\circ}$ Groove Angle with $1 \mathrm{~mm}$ gap

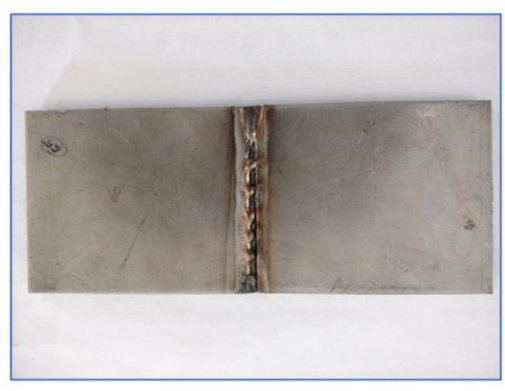

Groove Angle $70^{\circ}$

Figure 5. V-groove angles of the joints taken for experimentation trials

For the specimens in this proposed research work, joint edge geometries are prepared by milling process in the form of V-bevelled based on ANSI/AWS D 1.1 standard. Single V preparation with broad root face is welded with $60^{\circ}$ Groove angle, $60^{\circ}$ Groove angle with $1 \mathrm{~mm}$ gap and $70^{\circ}$ Groove angle. The penetration is not good in $60^{\circ}$ Groove angle with $1 \mathrm{~mm}$ gap and $70^{\circ}$ Groove angle as shown in Figure 5. Henceforth, V-groove angle is maintained at $60^{\circ}$ with zero mm root opening gap.

\subsection{DESIGN OF EXPERIMENTS USING RESPONSE SURFACE METHODOLOGY (RSM)}

The design of the experiment is an obvious approach particularly dealing with a fairly novel process as it reduces the number of experimental trials to be taken to establish the process as well as to distinguish the influence of process parameters on resultant quality. Response Surface Methodology (RSM) is a type of effective method to optimize the process conditions and to find the optimum value of the process input parameters. RSM is an inexpensive response surface model approximating the relationship between input variables and desired responses. This methodology concerns with a set of mathematical and statistical tools that can be used to predict the response influenced by the considered input variables, to optimize the response. By using RSM, it is possible to define the relationships between the responses and the main controllable input factors as well as it is a powerful technique, when all independent variables can be measurable, controllable and continuous along the experiment (with negligible error). The expression for the response surface can be 


$$
y=f\left(x_{1}, x_{2}, \ldots \ldots, x_{k}\right)
$$

If the response is well modeled by a linear function of the independent variables, the approximating function is the first-order model

$$
y=\beta_{0}+\beta_{1} x_{1}+\beta_{2} x_{2}+\cdots \ldots .+\epsilon
$$

The mathematical model of quadratic surface is described as Second Order Model

$$
y=\beta_{0}+\sum_{i=1}^{k} \beta_{i} x_{i}+\sum_{i=1}^{k} \beta_{i i} x_{i}{ }^{2}+\sum_{i<j} \sum \beta_{i i} x_{i} x_{j}+\epsilon
$$

The Design of Experiment (DOE) is carried out by RSM technique using Minitab- 17 statistical software by considering four factors and five levels of problem. The design matrix is chosen to conduct 32 experiments with 2 replications. Total number of experiments is 64 . Two level factorials with half fraction consists of thirty-two cube points with twelve centre points and twenty axial points are taken into analysis. The Table 4 depicts the levels and factors of the DOE required to optimize the values of welding input parameters using single response optimization to predict the quality of weld characteristics.

Table 4. Levels and Factors of the DOE

\begin{tabular}{|c|c|c|c|c|c|}
\hline Factors & Level 1(-2) & Level 2 (-1) & Level 3(0) & Level 4(+1) & Level 5(+2) \\
\hline Current $(\mathrm{Amp})$ & 240 & 260 & 280 & 300 & 320 \\
\hline Feed Rate $(\mathrm{m} / \mathrm{min})$ & 5 & 6 & 7 & 8 & 9 \\
\hline Welding Speed $(\mathrm{mm} / \mathrm{sec})$ & 10 & 12.5 & 15 & 17.5 & 20 \\
\hline Gas Flow $(1 / \mathrm{m})$ & 12.5 & 15 & 17.5 & 20 & 22.5 \\
\hline
\end{tabular}

Central Composite designs (CCD) approach of RSM is undertaken to be the better technique for five-level factorial designs which follows a class of approximately rotatable second order. It follows an independent quadratic design by requiring fewer experimental trials. The behaviour coordination is at the midpoints of edges on the process space in conjunction with the centre. In the present research, CCD technique has been instigated and experimental design matrix is expressed as shown in Table 5. The experimental tests were conducted as similar to the same design matrix. During the experimentation, it is necessary to eliminate the factors like environment factor, welding electrode variances, etc. that might affect the final results by adding unaccounted error. Further, in order to evaluate the robustness and suitability of the developed model with analysis of variance (ANOVA) study was carried out. The detailed analysis was implemented exclusively for the five designated response characteristics, namely Bead Width (mm), Bead Height (mm), Depth of Penetration (mm), Hardness (VHN) and Tensile Strength. Hence, from the characteristic correlations individual mathematical models were created for each response parameters.

Table 5. Design matrix of DOE

\begin{tabular}{|c|c|c|c|c|c|c|c|c|}
\hline Sl.No & \multicolumn{4}{|c|}{ Design Matrix } & Current & Feed rate & Welding speed & Gas Flow \\
\hline 1 & 0 & 0 & 0 & 0 & 280 & 7 & 15 & 17.5 \\
\hline 2 & 0 & 0 & 0 & 0 & 280 & 7 & 15 & 17.5 \\
\hline 3 & 2 & 0 & 0 & 0 & 320 & 7 & 15 & 17.5 \\
\hline 4 & 1 & 1 & -1 & 1 & 300 & 8 & 12.5 & 20 \\
\hline 5 & 0 & 0 & 0 & 0 & 280 & 7 & 15 & 17.5 \\
\hline 6 & -1 & 1 & -1 & 1 & 260 & 8 & 12.5 & 20 \\
\hline 7 & -1 & 1 & -1 & 1 & 260 & 8 & 12.5 & 20 \\
\hline 8 & -1 & -1 & 1 & -1 & 260 & 6 & 17.5 & 15 \\
\hline 9 & -1 & 1 & 1 & -1 & 260 & 8 & 17.5 & 15 \\
\hline
\end{tabular}




\begin{tabular}{|c|c|c|c|c|c|c|c|c|}
\hline 10 & 0 & -2 & 0 & 0 & 280 & 5 & 15 & 17.5 \\
\hline 11 & 0 & 0 & 0 & 0 & 280 & 7 & 15 & 17.5 \\
\hline 12 & -2 & 0 & 0 & 0 & 240 & 7 & 15 & 17.5 \\
\hline 13 & 1 & -1 & -1 & 1 & 300 & 6 & 12.5 & 20 \\
\hline 14 & -1 & -1 & 1 & -1 & 260 & 6 & 17.5 & 15 \\
\hline 15 & 0 & 0 & 0 & 0 & 280 & 7 & 15 & 17.5 \\
\hline 16 & 0 & 0 & 0 & 0 & 280 & 7 & 15 & 17.5 \\
\hline 17 & 0 & 2 & 0 & 2 & 280 & 9 & 15 & 17.5 \\
\hline 18 & -1 & -1 & -1 & -1 & 260 & 6 & 12.5 & 15 \\
\hline 19 & 1 & 1 & -1 & 1 & 300 & 8 & 12.5 & 15 \\
\hline 20 & 0 & 0 & -2 & 0 & 280 & 7 & 10 & 17.5 \\
\hline 21 & -1 & -1 & -1 & 1 & 260 & 6 & 12.5 & 20 \\
\hline 22 & -2 & 0 & 0 & 0 & 240 & 7 & 15 & 17.5 \\
\hline 23 & 1 & -1 & -1 & 1 & 300 & 6 & 12.5 & 20 \\
\hline 24 & 0 & 0 & 0 & -2 & 280 & 7 & 15 & 12.5 \\
\hline 25 & -1 & -1 & -1 & 1 & 260 & 6 & 12.5 & 20 \\
\hline 26 & 1 & 1 & -1 & -1 & 300 & 8 & 12.5 & 15 \\
\hline 27 & -1 & 1 & -1 & -1 & 260 & 8 & 12.5 & 15 \\
\hline 28 & -1 & -1 & 0 & 1 & 260 & 6 & 17.5 & 20 \\
\hline 29 & 1 & 1 & 1 & -1 & 300 & 8 & 17.5 & 15 \\
\hline 30 & 0 & 0 & 0 & 0 & 280 & 7 & 15 & 17.5 \\
\hline 31 & 0 & 0 & -2 & 0 & 280 & 7 & 10 & 17.5 \\
\hline 32 & 1 & 1 & 1 & 1 & 300 & 8 & 17.5 & 20 \\
\hline 33 & 0 & 0 & 0 & -2 & 280 & 7 & 15 & 12.5 \\
\hline 34 & -1 & 1 & -1 & -1 & 260 & 8 & 12.5 & 15 \\
\hline 35 & 0 & 0 & 0 & 0 & 280 & 7 & 15 & 17.5 \\
\hline 36 & 1 & 1 & 1 & 1 & 300 & 8 & 17.5 & 20 \\
\hline 37 & 0 & 0 & 0 & 0 & 280 & 7 & 15 & 17.5 \\
\hline 38 & -1 & 1 & 1 & 1 & 260 & 8 & 17.5 & 20 \\
\hline 39 & 1 & -1 & 1 & -1 & 300 & 6 & 17.5 & 15 \\
\hline 40 & -1 & 1 & 1 & 1 & 260 & 8 & 17.5 & 20 \\
\hline 41 & 2 & 0 & 0 & 0 & 320 & 7 & 15 & 17.5 \\
\hline 42 & 0 & 0 & 2 & 0 & 280 & 7 & 20 & 17.5 \\
\hline 43 & 0 & 0 & 0 & 0 & 280 & 7 & 15 & 17.5 \\
\hline 44 & 0 & 0 & 0 & 0 & 280 & 7 & 15 & 17.5 \\
\hline
\end{tabular}




\begin{tabular}{|c|c|c|c|c|c|c|c|c|}
\hline 45 & -1 & -1 & 1 & 1 & 260 & 6 & 17.5 & 20 \\
\hline 46 & -1 & -1 & -1 & -1 & 260 & 6 & 12.5 & 15 \\
\hline 47 & 0 & 0 & 0 & 0 & 280 & 7 & 15 & 17.5 \\
\hline 48 & -1 & 1 & 1 & -1 & 260 & 8 & 17.5 & 15 \\
\hline 49 & 0 & 0 & 0 & 2 & 280 & 7 & 15 & 22.5 \\
\hline 50 & 1 & -1 & 1 & 1 & 300 & 6 & 17.5 & 20 \\
\hline 51 & 1 & 1 & 1 & -1 & 300 & 8 & 17.5 & 15 \\
\hline 52 & 1 & 1 & -1 & 1 & 300 & 8 & 12.5 & 20 \\
\hline 53 & 1 & -1 & 1 & 1 & 300 & 6 & 17.5 & 20 \\
\hline 54 & 0 & 0 & 0 & 0 & 280 & 7 & 15 & 17.5 \\
\hline 55 & 1 & -1 & -1 & -1 & 300 & 6 & 12.5 & 15 \\
\hline 56 & 1 & -1 & -1 & -1 & 300 & 6 & 12.5 & 15 \\
\hline 57 & 0 & 0 & 0 & 0 & 280 & 7 & 15 & 17.5 \\
\hline 58 & 1 & -1 & 1 & -1 & 300 & 6 & 17.5 & 15 \\
\hline 59 & 0 & 2 & 0 & 0 & 280 & 9 & 15 & 17.5 \\
\hline 60 & 0 & -2 & 0 & 0 & 280 & 5 & 15 & 17.5 \\
\hline 61 & 0 & 0 & 0 & 2 & 280 & 7 & 15 & 22.5 \\
\hline 62 & 0 & 0 & 2 & 0 & 280 & 7 & 20 & 17.5 \\
\hline
\end{tabular}

\section{EXPERIMENTAL METHODOLOGY AND ANALYSIS}

In the current research, GMAW welding technique has been investigated on a $200 \mathrm{~mm} \times 20 \mathrm{~mm}$ dimension specimen of on ferritic stainless steel of series 400 (AISI: 430) grade and methodical experimentation procedure has been executed to optimize the multiple process parameters. The specimens are welded using the IRB1410 arc welding robot by changing the parameters such as Current Rating (Amp), Feed Rate $(\mathrm{m} / \mathrm{min})$, Welding Speed $(\mathrm{mm} / \mathrm{sec})$ and Gas Flow $(1 / \mathrm{m})$. The welded specimens are cut into the required testing dimensions of $200 \mathrm{~mm}$ x $20 \mathrm{~mm}$. The bead profiles of welded specimen such as Bead width (BW), Depth of penetration (DP), Bead Height (BH) are analyzed using profile projector. The micro vickers hardness (VHN) tests are performed on the etched transverse cross section of the welded zone using a load of $500 \mathrm{~g}$, which is applied for duration of 10 seconds. Three measurements in each welded zone are taken at regular intervals and the average hardness values are noted. The weld zones have higher hardness than the base metal zone. The variation of hardness across the weld metal is related to micro structural variation. The hardness values are higher in the weld metal area due to high dislocation density in the weld metal.

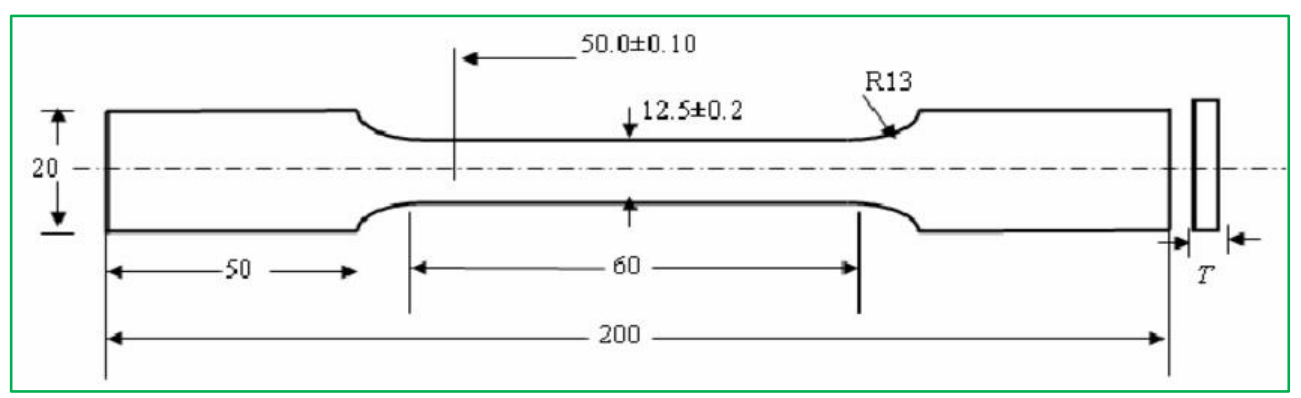

Figure 6. Tensile Standard dimensions 


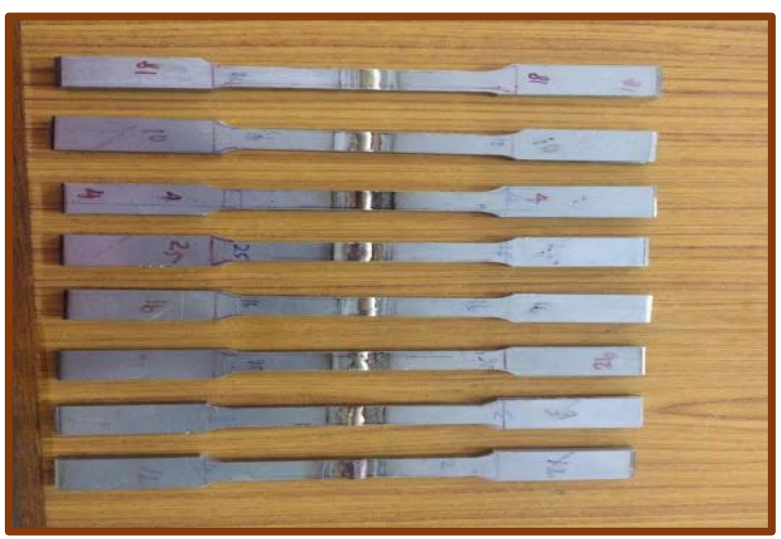

Figure 7. Dumb-bell shape

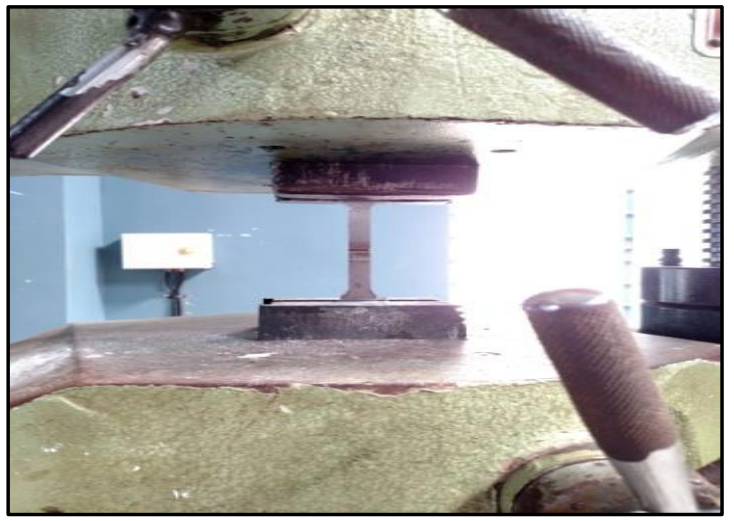

Figure 8. Universal Testing machine

The plates of AISI:430 stainless steel plates are welded by using industrial manipulator. The experiments are conducted as per the design factors. The values of Weld Bead Geometry (BH, DOP and BW) are noted for the corresponding input process parameters. The hardness value is identified for each specimen by using Vickers hardness tester and also the tensile strength is predicted for each specimen by using universal testing machine. Tensile test is conducted to study about the ultimate tensile strength of the weld joint. To achieve this, the maximum load can be applied to the welded specimen. For this test, the specimens are cut into dumbbell shape of standard dimensions as per the ANSI/AWS D1.1 standard as shown in Figure 7 which is made using L MILL 55 CNC machine as shown in Figure 8. The results obtained from Weld Bead Geometry (BH, DOP, and BW), Hardness (HD) test and Tensile (TS) test are tabulated in the Table 6. These experimental data are used to find the fitness function for designing optimization techniques.

Table 6. Experimental results holding bead geometry by varying input parameters

\begin{tabular}{|c|c|c|c|c|c|c|c|c|c|}
\hline Sl.No & $\begin{array}{c}\text { Current } \\
\text { Rating } \\
(\text { Amp) }\end{array}$ & $\begin{array}{c}\text { Feed } \\
\text { Rate } \\
(\mathbf{m} / \mathbf{m i n})\end{array}$ & $\begin{array}{c}\text { Welding } \\
\text { Speed } \\
(\mathbf{m m} / \mathbf{s e c})\end{array}$ & $\begin{array}{c}\text { Gas } \\
\text { Flow } \\
(\mathbf{1} / \mathbf{m})\end{array}$ & BH & DOP & BW & HD & TS \\
\hline 1 & 280 & 7 & 15 & 17.5 & 1.023 & 5.182 & 4.235 & 282.95 & 198.103 \\
\hline 2 & 280 & 7 & 15 & 17.5 & 1.023 & 5.188 & 4.234 & 287.45 & 258.649 \\
\hline 3 & 320 & 7 & 15 & 17.5 & 1.012 & 5.207 & 4.185 & 305.55 & 114.4828 \\
\hline 4 & 300 & 8 & 12.5 & 20 & 0.998 & 5.226 & 4.227 & 301.05 & 209.278 \\
\hline 5 & 280 & 7 & 15 & 17.5 & 1.025 & 5.189 & 4.239 & 289.45 & 306.897 \\
\hline 6 & 260 & 8 & 12.5 & 20 & 1.08 & 5.224 & 4.281 & 315.15 & 285.7241 \\
\hline 7 & 260 & 8 & 12.5 & 20 & 1.083 & 5.234 & 4.286 & 319.05 & 286.8966 \\
\hline 8 & 260 & 6 & 17.5 & 15 & 0.959 & 5.187 & 4.192 & 221.25 & 337.348 \\
\hline 9 & 260 & 8 & 17.5 & 15 & 0.996 & 5.149 & 4.218 & 219.65 & 316.5517 \\
\hline 10 & 280 & 5 & 15 & 17.5 & 0.99 & 5.219 & 4.246 & 293.55 & 332.6217 \\
\hline 11 & 280 & 7 & 15 & 17.5 & 1.023 & 5.185 & 4.235 & 290.95 & 265.518 \\
\hline 12 & 240 & 7 & 15 & 17.5 & 1.021 & 5.181 & 4.178 & 261.7 & 312.579 \\
\hline 13 & 300 & 6 & 12.5 & 20 & 0.983 & 5.208 & 4.223 & 299.15 & 223.4483 \\
\hline 14 & 260 & 6 & 17.5 & 15 & 0.958 & 5.112 & 4.194 & 224.95 & 338.096 \\
\hline 15 & 280 & 7 & 15 & 17.5 & 1.028 & 5.182 & 4.239 & 270.55 & 280 \\
\hline 16 & 280 & 7 & 15 & 17.5 & 1.022 & 5.189 & 4.233 & 292.5 & 275.482 \\
\hline 17 & 280 & 9 & 15 & 17.5 & 1.045 & 5.261 & 4.267 & 290.95 & 243.4483 \\
\hline 18 & 260 & 6 & 12.5 & 15 & 1.036 & 5.205 & 4.124 & 252.75 & 303.4483 \\
\hline 19 & 300 & 8 & 12.5 & 15 & 1.016 & 5.258 & 4.205 & 317.9 & 245.546 \\
\hline 20 & 280 & 7 & 10 & 17.5 & 1.078 & 5.239 & 4.175 & 307.05 & 385.845 \\
\hline 21 & 260 & 6 & 12.5 & 20 & 1.072 & 5.261 & 4.174 & 312.35 & 346.255 \\
\hline 22 & 240 & 7 & 15 & 17.5 & 1.029 & 5.184 & 4.179 & 264.3 & 314.828 \\
\hline 23 & 300 & 6 & 12.5 & 20 & 0.988 & 5.207 & 4.227 & 297.7 & 224.1765 \\
\hline
\end{tabular}




\begin{tabular}{|c|c|c|c|c|c|c|c|c|c|}
\hline 24 & 280 & 7 & 15 & 12.5 & 0.994 & 5.139 & 4.219 & 228.7 & 297.416 \\
\hline 25 & 260 & 6 & 12.5 & 20 & 1.072 & 5.268 & 4.176 & 309 & 344.379 \\
\hline 26 & 300 & 8 & 12.5 & 15 & 1.018 & 5.249 & 4.205 & 314.25 & 211.0345 \\
\hline 27 & 260 & 8 & 12.5 & 15 & 1.029 & 5.239 & 4.199 & 283.6 & 224.828 \\
\hline 28 & 260 & 6 & 17.5 & 20 & 0.998 & 5.207 & 4.152 & 240.05 & 424.5412 \\
\hline 29 & 300 & 8 & 17.5 & 15 & 1.087 & 5.221 & 4.171 & 254.35 & 347.241 \\
\hline 30 & 280 & 7 & 15 & 17.5 & 1.025 & 5.181 & 4.231 & 276.05 & 288.241 \\
\hline 31 & 280 & 7 & 10 & 17.5 & 1.079 & 5.229 & 4.171 & 315.95 & 377.278 \\
\hline 32 & 300 & 8 & 17.5 & 20 & 1.065 & 5.229 & 4.108 & 253.7 & 251.6581 \\
\hline 33 & 280 & 7 & 15 & 12.5 & 0.992 & 5.134 & 4.213 & 224 & 280.201 \\
\hline 34 & 260 & 8 & 12.5 & 15 & 1.029 & 5.235 & 4.191 & 280.9 & 227.8431 \\
\hline 35 & 280 & 7 & 15 & 17.5 & 1.025 & 5.182 & 4.231 & 289.45 & 251.385 \\
\hline 36 & 300 & 8 & 17.5 & 20 & 1.061 & 5.228 & 4.109 & 235.45 & 258.7562 \\
\hline 37 & 280 & 7 & 15 & 17.5 & 1.029 & 5.182 & 4.23 & 274.3 & 250.3448 \\
\hline 38 & 260 & 8 & 17.5 & 20 & 1.049 & 5.162 & 4.215 & 240.65 & 408.1681 \\
\hline 39 & 300 & 6 & 17.5 & 15 & 1.039 & 5.139 & 4.273 & 256.45 & 289.5419 \\
\hline 40 & 260 & 8 & 17.5 & 20 & 1.044 & 5.168 & 4.211 & 237.65 & 403.793 \\
\hline 41 & 320 & 7 & 15 & 17.5 & 1.018 & 5.209 & 4.18 & 308.3 & 154.6412 \\
\hline 42 & 280 & 7 & 20 & 17.5 & 1.064 & 5.157 & 4.124 & 238.95 & 459.358 \\
\hline 43 & 280 & 7 & 15 & 17.5 & 1.028 & 5.182 & 4.231 & 273.45 & 301.207 \\
\hline 44 & 280 & 7 & 15 & 17.5 & 1.025 & 5.179 & 4.237 & 283.05 & 270.3119 \\
\hline 45 & 260 & 6 & 17.5 & 20 & 0.991 & 5.203 & 4.15 & 240.45 & 426.2069 \\
\hline 46 & 260 & 6 & 12.5 & 15 & 1.031 & 5.209 & 4.129 & 253.95 & 310.1831 \\
\hline 47 & 280 & 7 & 15 & 17.5 & 1.023 & 5.182 & 4.229 & 281.15 & 273.1034 \\
\hline 48 & 260 & 8 & 17.5 & 15 & 0.993 & 5.149 & 4.217 & 218.5 & 319.3581 \\
\hline 49 & 280 & 7 & 15 & 22.5 & 1.016 & 5.202 & 4.193 & 226.3 & 253.916 \\
\hline 50 & 300 & 6 & 17.5 & 20 & 0.998 & 5.209 & 4.151 & 261.45 & 279.278 \\
\hline 51 & 300 & 8 & 17.5 & 15 & 1.085 & 5.221 & 4.177 & 255.65 & 316.748 \\
\hline 52 & 300 & 8 & 12.5 & 20 & 0.991 & 5.228 & 4.221 & 297.25 & 211.586 \\
\hline 53 & 300 & 6 & 17.5 & 20 & 0.996 & 5.208 & 4.15 & 258.45 & 282.981 \\
\hline 54 & 280 & 7 & 15 & 17.5 & 0.992 & 5.182 & 4.238 & 269.3 & 294.0586 \\
\hline 55 & 300 & 6 & 12.5 & 15 & 1.016 & 5.163 & 4.258 & 268.9 & 284.8276 \\
\hline 56 & 300 & 6 & 12.5 & 15 & 1.011 & 5.167 & 4.25 & 266.75 & 276.0861 \\
\hline 57 & 280 & 7 & 15 & 17.5 & 1.029 & 5.189 & 4.23 & 272.55 & 255.6824 \\
\hline
\end{tabular}




\begin{tabular}{|c|c|c|c|c|c|c|c|c|c|}
58 & 300 & 6 & 17.5 & 15 & 1.031 & 5.137 & 4.269 & 250.95 & 295.1864 \\
\hline 59 & 280 & 9 & 15 & 17.5 & 1.048 & 5.263 & 4.241 & 287.6 & 240.6161 \\
\hline 60 & 280 & 5 & 15 & 17.5 & 0.991 & 5.213 & 4.245 & 294.6 & 328.9655 \\
\hline 61 & 280 & 7 & 15 & 22.5 & 1.019 & 5.206 & 4.199 & 228.95 & 248.348 \\
\hline 62 & 280 & 7 & 20 & 17.5 & 1.069 & 5.159 & 4.129 & 232.45 & 464.828 \\
\hline
\end{tabular}

\subsection{MATHEMATICAL MODEL: REGRESSION ANALYSIS}

In this section, single response optimization using RSM technique statistical results are used for the analysis of bead height (BH), depth of penetration (DOP), bead width (BW), hardness (HD) and tensile strength (TS). The response function for $\mathrm{BH}$ is expressed as:

\section{Bead Height $=1.904+0.00004 \mathrm{~A}-0.0859 \mathrm{~B}-0.22784 \mathrm{C}+0.12313 \mathrm{D}-0.000003 \mathrm{~A} * \mathrm{~A}-0.001751 \mathrm{~B} * \mathrm{~B}$ $+0.001880 \mathrm{C} * \mathrm{C} \quad-0.000810 \mathrm{D} * \mathrm{D}+\mathbf{0 . 0 0 0 1 1 4} \mathrm{A} * \mathrm{~B} \quad+0.000491 \mathrm{~A} * \mathrm{C} \quad \mathbf{- 0 . 0 0 0 3 6 3} \mathrm{A} * \mathrm{D}+\mathbf{0 . 0 0 4 6 8 8} \mathrm{B} * \mathrm{C}$ $+0.001262 \mathrm{~B} * \mathrm{D}$ \\ (4)}

By taking Equation 4 established by regression analysis for bead height, analysis of variance results for the response surface cubic model is given in Table 7. The Model F-value of 124.27 indicates that the model is significant. In fact, it is chance of about $0.01 \%$ to get large F-Value mostly could occur due to noise. The obtained model terms are significant due to the "Prob > F" values smaller than 0.05. In this case A, B, D,C, D, AA, BB, CC, DD, AB, AC, AD, $\mathrm{BC}, \mathrm{BD}$ are significant model terms. Values greater than 0.1 indicate the model terms are not significant. If there are many insignificant model terms, model reduction may improve the model. The "Lack of Fit F-value" of 0.88 shows that lack of fit is not significant relative to the pure error. There is a $56.4 \%$ chance that large $\mathrm{F}$ - value of lack of fit could occur due to noise. Non-significant lack of fit is good. From Table 7, the "Pred. R-squared" of 0.9592 is in sensible agreement with the 'Adj. R-squared' of 0.9633. The corresponding residual plot for the bead height is given in Figure 9.

Table 7. ANOVA table for bead height

\begin{tabular}{|c|c|c|c|c|c|}
\hline Source & DF & Adj SS & Adj MS & F-Value & P-Value \\
\hline Model & 13 & 0.0564 & 0.004 & 124.27 & 0 \\
\hline Linear & 4 & 0.011 & 0.0027 & 79.06 & 0 \\
\hline A & 1 & 0.0001 & 0.0001 & 3.53 & 0.067 \\
\hline B & 1 & 0.0093 & 0.0093 & 266.76 & 0 \\
\hline C & 1 & 0.0004 & 0.0004 & 13.59 & 0.001 \\
\hline D & 1 & 0.0011 & 0.0011 & 32.36 & 0 \\
\hline Square & 4 & 0.0107 & 0.0026 & 76.73 & 0 \\
\hline A*A & 1 & 0.0001 & 0.0001 & 3.10 & 0.085 \\
\hline B*B & 1 & 0.0001 & 0.0001 & 5.02 & 0.03 \\
\hline C*C & 1 & 0.0078 & 0.0078 & 225.87 & 0 \\
\hline D*D & 1 & 0.0014 & 0.0014 & 41.85 & 0 \\
\hline 2-Way Interaction & 5 & 0.0347 & 0.0057 & 198.47 & 0 \\
\hline A*B & 1 & 0.0001 & 0.0001 & 4.76 & 0.035 \\
\hline A*C & 1 & 0.0192 & 0.0192 & 550.93 & 0 \\
\hline A*D & & 0.0105 & 0.0105 & 301.79 & 0 \\
\hline
\end{tabular}




\begin{tabular}{|c|c|c|c|c|c|}
\hline $\mathrm{B} * \mathrm{C}$ & 1 & 0.0043 & 0.0043 & 125.72 & 0 \\
\hline $\mathrm{B} * \mathrm{D}$ & 1 & 0.0003 & 0.0003 & 9.12 & 0.004 \\
\hline Error & 48 & 0.0016 & 0.00003 & & \\
\hline Lack of fit & 11 & 0.0003 & 0.00003 & 0.88 & 0.564 \\
\hline Pure Error & 37 & 0.0013 & 0.00003 & & \\
\hline Total & 61 & 0.0581 & & & \\
\hline & & & & & \\
\hline Model Summary & & & & & \\
\hline S & & R-sq & R-sq(adj) & R-sq(pred) & \\
\hline 0.00593 & & $97.11 \%$ & $96.33 \%$ & $95.92 \%$ & \\
\hline
\end{tabular}

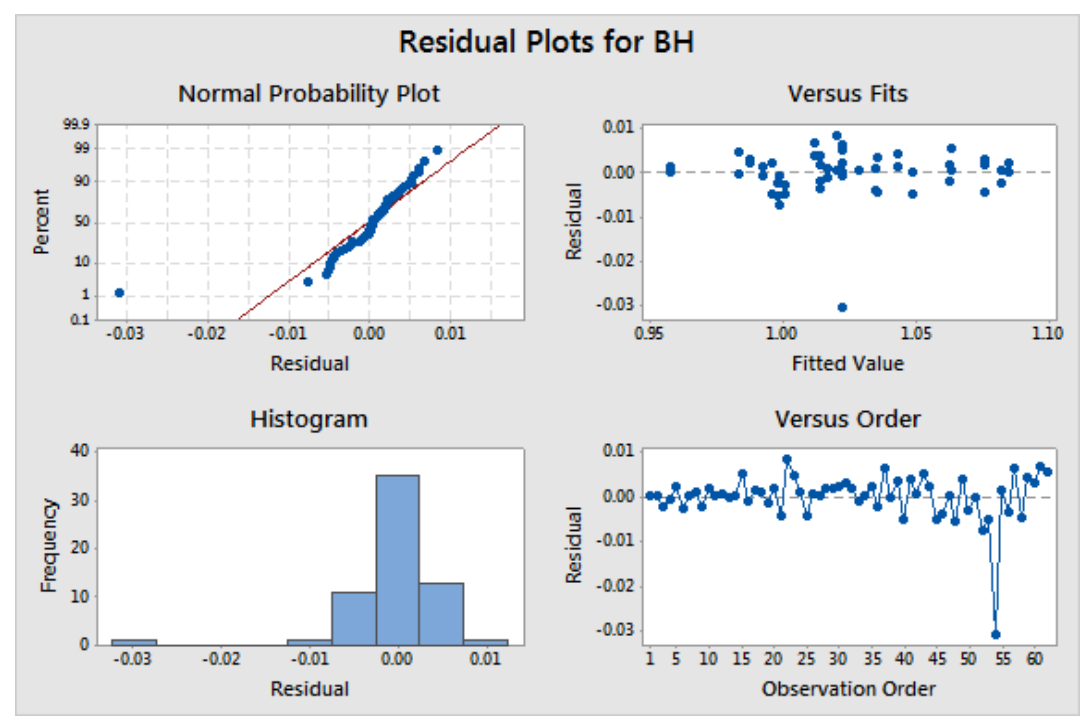

Figure 9. Obtained residual plot for the bead height parameter

By taking other parameter like depth of penetration, the regression equation is given as:

\section{Penetration $=8.507-0.01416 \mathrm{~A}-0.2962 \mathrm{~B}-0.1071 \mathrm{C}+0.05067 \mathrm{D}+0.000009 \mathrm{~A} * \mathrm{~A}+0.01434 \mathrm{~B} * \mathrm{~B}$ $+0.000574 C * C-0.000456 D * D+0.000803 A * B+0.000265 A * C-0.001000 B * C-0.005925 B * D$ $+0.000840 C^{*} D$

Based on the Equation 5 for weld penetration, analysis of variance results for the response surface cubic model is given in Table 8. The Model F-value of 60.47 indicates that the model is significant. In fact, it is chance of about $0.01 \%$ to get large F-Value mostly could occur due to noise. The obtained model terms are significant due to the "Prob > F" values smaller than 0.05. In this case A, B, C, D, AA, BB, CC, DD, AB, BC, BD, CD are significant model terms. Values greater than 0.1 indicate the model terms are not significant. If there are many insignificant model terms, model reduction may improve the model. The "Lack of Fit F-value" of 0.88 shows that lack of fit is not significant relative to the pure error. There is a $36.1 \%$ chance that large $\mathrm{F}$ - value of lack of fit could occur due to noise. Nonsignificant lack of fit is good. From Table 8, the "Pred. R-squared" of 0.8953 is in sensible agreement with the "Adj. R-squared' of 0.9269. The corresponding residual plot for the penetration is given in Figure 10.

Table 8. ANOVA table for depth of penetration

\begin{tabular}{|c|c|c|c|c|c|}
\hline Source & DF & Adj SS & Adj MS & F-Value & P-Value \\
\hline Model & 13 & 0.071 & 0.005 & 60.47 & 0 \\
\hline Linear & 4 & 0.0354 & 0.0088 & 98.31 & 0 \\
\hline
\end{tabular}




\begin{tabular}{|c|c|c|c|c|c|}
\hline A & 1 & 0.0007 & 0.0007 & 8.16 & 0.006 \\
\hline B & 1 & 0.0055 & 0.0055 & 60.99 & 0 \\
\hline C & 1 & 0.019 & 0.019 & 210.98 & 0 \\
\hline D & 1 & 0.0102 & 0.0102 & 113.12 & 0 \\
\hline Square & 4 & 0.0134 & 0.0033 & 37.34 & 0 \\
\hline B*A & 1 & 0.0006 & 0.0006 & 7.33 & 0.009 \\
\hline C*C & 1 & 0.0117 & 0.0117 & 130.28 & 0 \\
\hline D*D & 1 & 0.0007 & 0.0007 & 8.16 & 0.006 \\
\hline 2-Way Interaction & 1 & 0.0004 & 0.0004 & 5.15 & 0.028 \\
\hline A*B & 1 & 0.022 & 0.0036 & 48.71 & 0 \\
\hline A*C & 1 & 0.0082 & 0.0082 & 91.48 & 0 \\
\hline A*D & & 0.0056 & 0.0056 & 62.25 & 0 \\
\hline B*C & 1 & 0.0002 & 0.0002 & 2.22 & 0.32 \\
\hline B*D & 1 & 0.007 & 0.007 & 77.80 & 0 \\
\hline C*D & 1 & 0.0008 & 0.0008 & 9.77 & 0.003 \\
\hline Error & 48 & 0.0042 & 0.00009 & & \\
\hline Lack of fit & 10 & 0.001 & 0.0001 & 1.14 & 0.361 \\
\hline Pure Error & 37 & 0.0032 & 0.00008 & & \\
\hline Total & 61 & 0.075 & & & \\
\hline & & & & & \\
\hline Model Summary & & & & & \\
\hline S & & R-sq & R-sq(adj) & R-sq(pred) & \\
\hline 0.0094 & & $94.25 \%$ & $92.69 \%$ & $89.53 \%$ & \\
\hline & & & & & \\
\hline & & & 0 & & \\
\hline & & & & \\
\hline
\end{tabular}

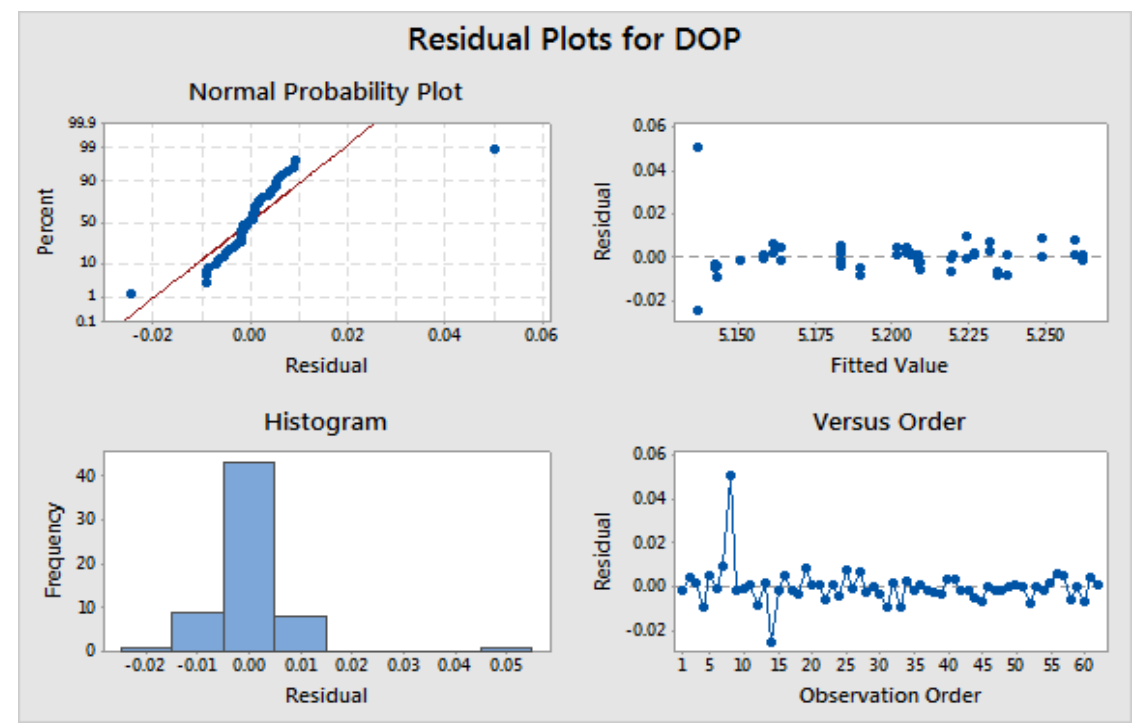

Figure 10. Residual plots of Depth of penetration

By following, depth of penetration, the bead height mathematical expression is given as

Bead Width $=\quad-5.57261+0.0383208 \mathrm{~A}+0.3287 \mathrm{~B}+0.258390 \mathrm{C}+0.157675 \mathrm{D}-0.000032673 \mathrm{~A}^{2}+0.0042433 \mathrm{~B}^{2}-$ $0.00332107 C^{2}-0.00107107 D^{2}-0.00141406 A B-0.000248125 A C-0.000358125 A D-0.00448750 B C+0.00451250 B D-$ 0.00359500CD 
The bead width with regression model representation of Equation 6, respective analysis of variance results for the response surface cubic model is given in Table 9. The Model F-value of 359.32 indicates that the model is significant. In fact, it is chance of about $0.01 \%$ to get large F-Value mostly could occur due to noise. The obtained model terms are significant due to the "Prob > F" values smaller than 0.05. In this case A, B, C, D, A $\mathrm{A}^{2}, \mathrm{~B}^{2}, \mathrm{C}^{2}, \mathrm{AB}, \mathrm{AC}, \mathrm{AD}, \mathrm{BC}$, $\mathrm{BD}, \mathrm{CD}$ are significant model terms. Values greater than 0.1 indicate the model terms are not significant. If there are many insignificant model terms, model reduction may improve the model. The "Lack of Fit F-value" of 0.88 shows that lack of fit is not significant relative to the pure error. There is a $0.016 \%$ chance that large $\mathrm{F}$ - value of lack of fit could occur due to noise. Non-significant lack of fit is good. From Table 9, the "Pred. R-squared" of 0.9827 is in sensible agreement with the 'Adj. R-squared' of 0.9880 . The corresponding residual plot for the penetration is given in Figure 11.

Table 9. ANOVA table for bead width

\begin{tabular}{|c|c|c|c|c|c|}
\hline \\
\hline Source & DF & Adj SS & Adj MS & F-Value & P-Value \\
\hline Model & 14 & 0.1112 & 0.0079 & 359.32 & 0 \\
\hline Linear & 4 & 0.0104 & 0.0002 & 118.11 & 0 \\
\hline A & 1 & 0.0003 & 0.0003 & 16.17 & 0 \\
\hline $\mathrm{B}$ & 1 & 0.0006 & 0.0006 & 31.56 & 0 \\
\hline $\mathrm{C}$ & 1 & 0.0076 & 0.0007 & 344.92 & 0 \\
\hline $\mathrm{D}$ & 1 & 0.0017 & 0.0017 & 79.8 & 0 \\
\hline Square & 4 & 0.0357 & 0.0089 & 404.08 & 0 \\
\hline $\mathrm{A} * \mathrm{~A}$ & 1 & 0.0097 & 0.0097 & 441.86 & 0 \\
\hline $\mathrm{B} * \mathrm{~B}$ & 1 & 0.001 & 0.001 & 46.58 & 0 \\
\hline $\mathrm{C} * \mathrm{C}$ & 1 & 0.0246 & 0.0246 & 1114.56 & 0 \\
\hline $\mathrm{D} * \mathrm{D}$ & 1 & 0.0025 & 0.0025 & 115.93 & 0 \\
\hline 2-Way Interaction & 6 & 0.065 & 0.01 & 490.29 & 0 \\
\hline $\mathrm{A} * \mathrm{~B}$ & 1 & 0.0255 & 0.0255 & 1157.72 & 0 \\
\hline $\mathrm{A}^{*} \mathrm{C}$ & 1 & 0.0049 & 0.0049 & 222.79 & 0 \\
\hline$A * D$ & & 0.0102 & 0.0102 & 464.1 & 0 \\
\hline $\mathrm{B} * \mathrm{C}$ & 1 & 0.004 & 0.004 & 182.18 & 0 \\
\hline $\mathrm{B} * \mathrm{D}$ & 1 & 0.004 & 0.004 & 184.21 & 0 \\
\hline $\mathrm{C} * \mathrm{D}$ & 1 & 0.0161 & 0.0161 & 730.74 & 0 \\
\hline Error & 47 & 0.001 & 0.00002 & & \\
\hline Lack of fit & 10 & 0.0003 & 0.00003 & 1.6 & 0.145 \\
\hline Pure Error & 37 & 0.0007 & 0.00002 & & \\
\hline Total & 61 & 0.1122 & & & \\
\hline \multicolumn{6}{|l|}{ Model Summary } \\
\hline $\mathrm{S}$ & & $\mathrm{R}$-sq & R-sq(adj) & R-sq(pred) & \\
\hline 0.0047 & & $99.07 \%$ & $98.80 \%$ & $98.27 \%$ & \\
\hline
\end{tabular}




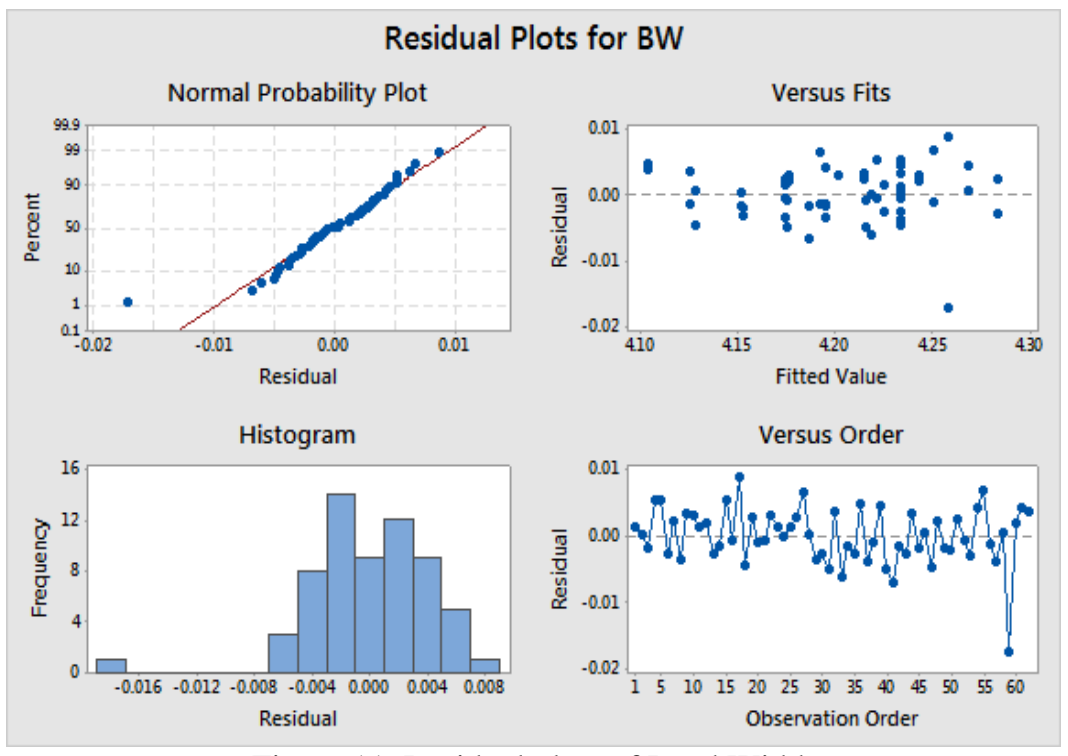

Figure 11. Residual plots of Bead Width

Now, hardness estimation is conducted with the representation of the regression equation is expressed as

\section{Hardness $=-1464+1.655 \mathrm{~A}+45.5 \mathrm{~B}+6.4 \mathrm{C}+147.6 \mathrm{D}+0.0017527+2.3 \mathrm{~B}^{2}-0.354 \mathrm{C}^{2}-2.219 \mathrm{D}^{2}++0.0919 \mathrm{AC}-0.1499 \mathrm{AD}-$ 2.58750BC -2.09375BD- 0.728000CD

From the regression analysis given by Equation 7, respective analysis of variance results for the response surface cubic model is given in Table 10. The Model F-value of 51.89 indicates that the model is significant. In fact, it is chance of about $0.01 \%$ to get large F-Value mostly could occur due to noise. The obtained model terms are significant due to the "Prob > F" values smaller than 0.05. In this case A, B, C, D, A2 , B ${ }^{2}, \mathrm{C}^{2}, \mathrm{D}^{2}, \mathrm{AC}, \mathrm{AD}, \mathrm{BC}, \mathrm{BD}, \mathrm{CD}$ are significant model terms. Values greater than 0.1 indicate the model terms are not significant. If there are many insignificant model terms, model reduction may improve the model. The "Lack of Fit F-value" of 0.068 shows that lack of fit is not significant relative to the pure error. There is a $0.041 \%$ chance that large $\mathrm{F}$ - value of lack of fit could occur due to noise. Non-significant lack of fit is good. From Table 10, the "Pred. R-squared" of 0.8776 is in sensible agreement with the 'Adj. R-squared' of 0.9092. The corresponding residual plot for the penetration is given in Figure 12.

Table 10. ANOVA table for Hardness

\begin{tabular}{|c|c|c|c|c|c|}
\hline Source & DF & Adj SS & Adj MS & F-Value & P-Value \\
\hline Model & 12 & 48798.1 & 4066.5 & 51.89 & 0 \\
\hline Linear & 4 & 31465.4 & 7866.4 & 100.38 & 0 \\
\hline A & 1 & 3253.8 & 3253.8 & 41.52 & 0 \\
\hline B & 1 & 256.7 & 256.7 & 3.28 & 0.076 \\
\hline C & 1 & 26287.6 & 26287.6 & 335.45 & 0 \\
\hline D & 1 & 1667.3 & 1667.3 & 21.28 & 0 \\
\hline Square & 3 & 11981.3 & 3993.8 & 50.96 & 0 \\
\hline B*B & 1 & 307.2 & 307.2 & 3.92 & 0.053 \\
\hline C*C & 1 & 283.6 & 283.6 & 3.62 & 0.063 \\
\hline D*D & 1 & 11123.8 & 11123.8 & 141.95 & 0 \\
\hline 2-Way Interaction & 5 & 5351.5 & 1070.3 & 13.66 & 0 \\
\hline A*C & 1 & 676.2 & 676.2 & 8.63 & 0.005 \\
\hline A*D & 1 & 1797.0 & 1797.0 & 22.93 & 0 \\
\hline
\end{tabular}




\begin{tabular}{|c|c|c|c|c|c|}
\hline $\mathrm{B} * \mathrm{C}$ & 1 & 1339.0 & 1339.0 & 17.09 & 0 \\
\hline $\mathrm{B} * \mathrm{D}$ & 1 & 876.8 & 876.8 & 11.19 & 0.002 \\
\hline $\mathrm{C} * \mathrm{D}$ & 1 & 662.5 & 662.5 & 8.45 & 0.005 \\
\hline Error & 49 & 3839.9 & 78.4 & & \\
\hline Lack of fit & 12 & 2649.8 & 220.8 & 6.87 & 0.000 \\
\hline Pure Error & 37 & 1190 & 32.2 & & \\
\hline Total & 61 & 52638 & & & \\
\hline & & & & & \\
\hline Model Summary & & & & & \\
\hline S & & R-sq & R-sq(adj) & R-sq(pred) & \\
\hline 8.85237 & & $92.71 \%$ & $90.92 \%$ & $87.76 \%$ & \\
\hline
\end{tabular}

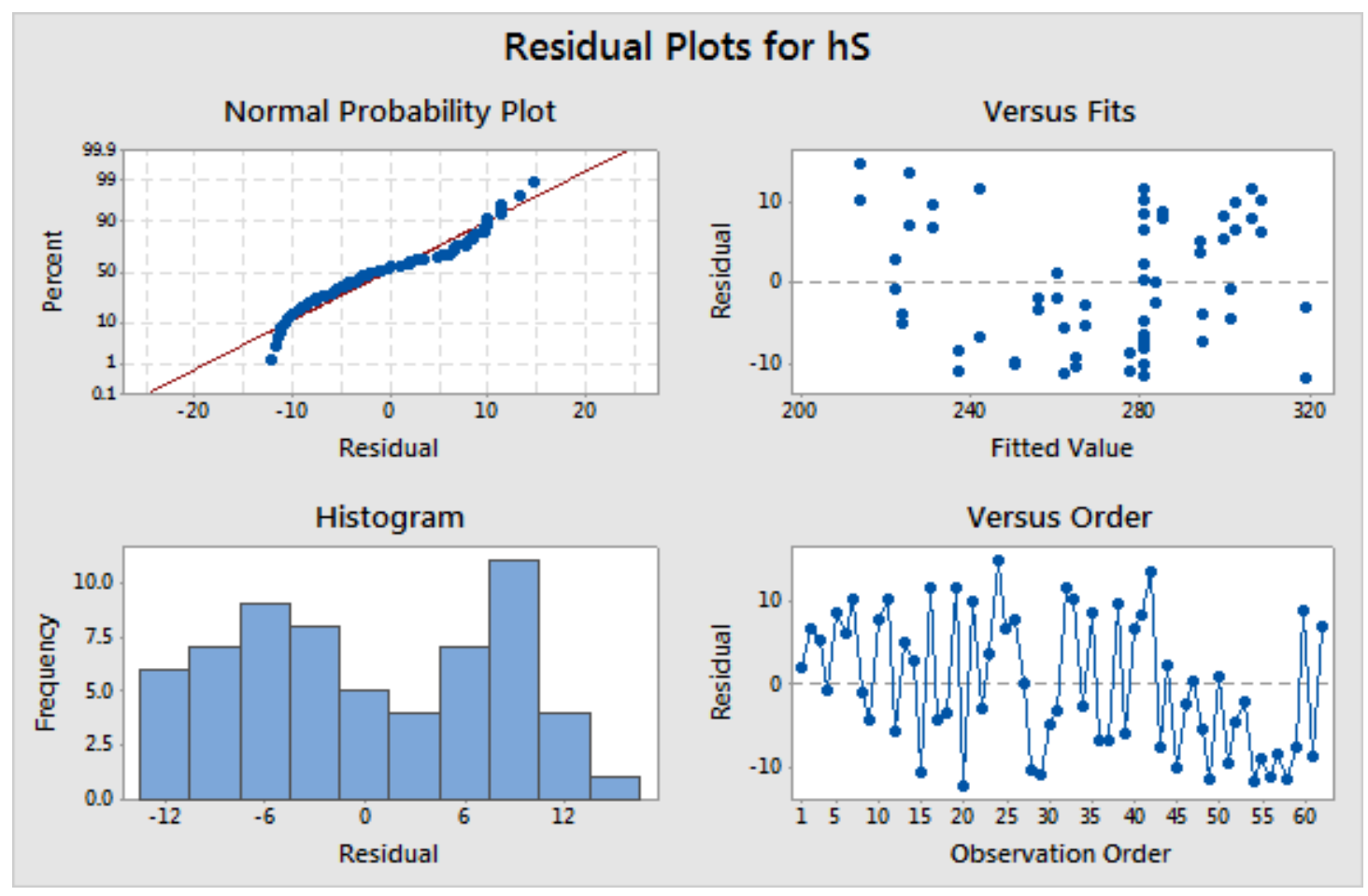

Figure 12. Residual plots of Hardness

Finally, the tensile strength evaluation is followed by the regression equation is

\section{Tensile strength $=-2282+23.87 \mathrm{~A}-195.3 \mathrm{~B}-162.0 \mathrm{C}+153.4 \mathrm{D}-0.03039 \mathrm{~A}^{2}+5.963 \mathrm{C}^{2}+0.396 \mathrm{AB}-0.1307 \mathrm{AC}$ 0.545848AD+4.48953BC \\ (8)}

By following Equation 8, its corresponding analysis of variance results for the response surface cubic model is given in Table 11. The Model F-value of 52.06 indicates that the model is significant. In fact, it is chance of about $0.023 \%$ to get large F-Value mostly could occur due to noise. The obtained model terms are significant due to the "Prob $>$ F" values smaller than 0.05 . In this case $\mathrm{A}, \mathrm{B}, \mathrm{C}, \mathrm{D}, \mathrm{A}^{2}, \mathrm{AB}, \mathrm{AC}, \mathrm{AD}, \mathrm{BC}$ are significant model terms. Values greater than 0.1 indicate the model terms are not significant. If there are many insignificant model terms, model reduction may improve the model. The "Lack of Fit F-value" of 0.027 shows that lack of fit is not significant relative to the pure error. There is a $0.041 \%$ chance that large $\mathrm{F}$ - value of lack of fit could occur due to noise. Non-significant lack of fit 
is good. From Table 11, the "Pred. R-squared" of 0.8751 is in sensible agreement with the 'Adj. R-squared' of 0.8943. The corresponding residual plot for the penetration is given in Figure 13.

Table 11. ANOVA table for Tensile Strength

\begin{tabular}{|c|c|c|c|c|c|}
\hline Source & DF & Adj SS & Adj MS & F-Value & P-Value \\
\hline Model & 10 & 249736 & 24973.6 & 52.60 & 0 \\
\hline Linear & 4 & 123399 & 30849.8 & 64.98 & 0 \\
\hline A & 1 & 68464 & 68464.4 & 144.20 & 0 \\
\hline B & 1 & 13873 & 13872.6 & 29.22 & 0 \\
\hline C & 1 & 40952 & 40952.4 & 86.26 & 0 \\
\hline D & 1 & 110 & 109.7 & 0.23 & 0.633 \\
\hline Square & 2 & 95093 & 47546.6 & 100.14 & 0 \\
\hline$A^{*}$ A & 1 & 8626 & 8626.2 & 18.17 & 0 \\
\hline $\mathrm{C}^{*} \mathrm{C}$ & 1 & 81095 & 81095.1 & 170.81 & 0 \\
\hline 2-Way Interaction & 4 & 31244 & 7810.9 & 16.45 & 0 \\
\hline $\mathrm{A}^{*} \mathrm{~B}$ & 1 & 2010 & 2010.0 & 4.23 & 0.045 \\
\hline $\mathrm{A}^{*} \mathrm{C}$ & 1 & 1366 & 1366.3 & 2.88 & 0.096 \\
\hline $\mathrm{A}^{*} \mathrm{D}$ & 1 & 23836 & 23836.0 & 50.20 & 0 \\
\hline $\mathrm{B}$ C & 1 & 4031 & 4031.2 & 8.49 & 0.005 \\
\hline Error & 51 & 24214 & 474.8 & & \\
\hline Lack of fit & 14 & 12350 & 882.2 & 2.75 & 0.007 \\
\hline Pure Error & 37 & 11863 & 320.6 & & \\
\hline Total & 61 & 273949 & & & \\
\hline & & & & & \\
\hline Model Summary & & & & & \\
\hline S & & R-sq & R-sq(adj) & R-sq(pred) & \\
\hline 21.7894 & & $91.16 \%$ & $89.43 \%$ & $87.51 \%$ & \\
\hline
\end{tabular}

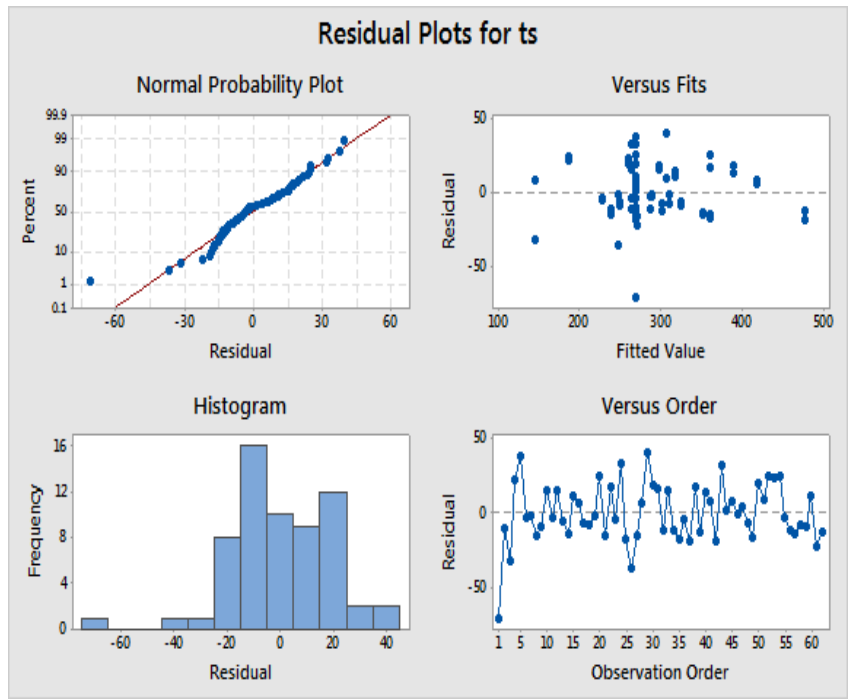

Figure 13. Residual plots of Tensile Strength

The suitability of established models has been verified by using analysis of variance technique (ANOVA). On accordance with the ANOVA method, if the evaluated F-ratio of the regression model is less than the value of F-ratio 
from F-statistics over the confidence level of 95\%, then the established model is well fit. Tables 7-11 provides the ANOVA results for bead height (BH), bead width (BW), depth of penetration (DP), hardness (HS) and tensile strength (TS) respectively. From the table, it is inferred that the created regression model for every parameter is found to best fit with respect to the $95 \%$ confidence level. Also, by holding P-value less than 0.05 indicates that the model terms are significant for model building.

\subsection{CONFIRMATION TEST FOR SINGLE RESPONSE OPTIMIZATION}

The optimized parameters have been confirmed by accompanying three confirmatory tests. The obtained optimum value through desirability function in RSM is given in Table 12. For confirmatory test, new set of process parameters are considered for welding technique execution. When the welding run is performed its corresponding bead profile geometry, hardness and tensile strength are measured.

Table 12. Results of optimal parameters values by RSM

\begin{tabular}{|c|c|c|c|c|c|c|c|c|}
\hline BH & DOP & BW & HD & TS & C & FR & WS & GF \\
\hline 1.082 & 5.207 & 4.282 & 312.02 & 154.51 & 320 & 9 & 10 & 12.5 \\
\hline
\end{tabular}

Table 13. Confirmation test results of single response optimization

\begin{tabular}{|c|c|c|c|c|}
\hline Sl. No & Parameters & $\begin{array}{c}\text { Optimized parameters with } \\
\text { predicted values }\end{array}$ & $\begin{array}{c}\text { Experimentally } \\
\text { observed Values }\end{array}$ & $\%$ of error \\
\hline 1 & Current & $320 \mathrm{Amp}$ & $320 \mathrm{Amp}$ & - \\
\hline 2 & Feed Rate & $9 \mathrm{~m} / \mathrm{min}$ & $9 \mathrm{~m} / \mathrm{min}$ & - \\
\hline 3 & Welding Speed & $10 \mathrm{~mm} / \mathrm{sec}$ & $10 \mathrm{~mm} / \mathrm{sec}$ & - \\
\hline 4 & Gas flow & $12.5 \mathrm{l} / \mathrm{min}$ & $12.5 \mathrm{l} / \mathrm{min}$ & - \\
\hline 5 & Bead Height & $1.082 \mathrm{~mm}$ & $5.096 \mathrm{~mm}$ & -1.29 \\
\hline 6 & Depth of Penetration & $5.207 \mathrm{~mm}$ & $4.119 \mathrm{~mm}$ & 1.497 \\
\hline 7 & Bead Width & $4.282 \mathrm{~mm}$ & $314.56 \mathrm{VHN}$ & -0.806 \\
\hline 8 & Hardness & $312.02 \mathrm{VHN}$ & $152.32 \mathrm{~N} / \mathrm{mm} 2$ & 1.417 \\
\hline 9 & Tensile Strength & $154.51 \mathrm{~N} / \mathrm{mm} 2$ & & \\
\hline
\end{tabular}

The confirmation test is carried out using optimal value and average values of three experimented results are tabulated in Table 13. From the Table 13, it is clearly seen that the experimental results of bead profiles have come closer to the predicted values and also the error is negligible. Further, it is confirmed that the percentage error is less than 1.5\% i.e. percentage error is within the acceptable range.

\section{MULTI-RESPONSE OPTIMIZATION}

In addition to the single response optimization, for the synchronized optimization of all the five performance characteristics, a multi-objective optimization technique for the process parameters has also been investigated. For this analysis, PSO (Particle Swarm Optimization) and Firefly algorithm (FA) are considered in which developing optimization function incudes all the response characteristics. In this present work, the implementing PSO and Firefly algorithms are employed to identify the fine optimized values of input parameters, weld geometries and material properties.

\subsection{PARICLE SWARM OPTIMIZATION}

Particle swarm optimization (PSO) is a population based stochastic optimization technique inspired by social behaviour of bird flocking or fish schooling. The system is initialized with a population of random solutions and searches for optima by updating generations. In PSO, the potential solutions, called particles, fly through the problem space by following the current optimum particles. This concept consists of, a teach time step, changing the velocity of (accelerating) each particle towards its 'pbest (best solution (fitness) achieved so far)'and 'lbest (local best)' locations. Acceleration is weighted by a random term, with separate random numbers being generated for acceleration 
toward 'pbest' and 'lbest' locations. Another "best" value that is tracked by the particle swarm optimizer obtained so far by any particle in the population is termed as "gbest (global best)". Figure 14 shows the flowchart of the PSO algorithm executed in the present work.

Input: f: the function to optimise; s: the swarm size; d: the problem dimension

Xmin, Xmax : Lower and upper boundaries for decision variables

Vmin, Vmax : Lower and upper boundaries for particles velocities

Output: $\mathrm{x}^{*}$ : the best particle position found (global best); $\mathrm{f}^{*}$ : the best fitness value found;

Initialise: position $\mathrm{x}_{\mathrm{i}}=\left(\mathrm{x}_{\mathrm{il}}, \ldots, \mathrm{x}_{\mathrm{id}}\right)$ and velocity $\mathrm{v}_{\mathrm{i}}=\left(\mathrm{v}_{\mathrm{il}}, \ldots, \mathrm{v}_{\mathrm{id}}\right)$, for all particles in problem space; evaluate $\mathrm{f}\left(\mathrm{x}_{\mathrm{i}}\right)$ in $\mathrm{d}$ variables and get pbest $\mathrm{i}_{\mathrm{i}},(\mathrm{i}=1, \ldots, \mathrm{s})$; gbest $\leftarrow$ best of pbest $\mathrm{i}_{\mathrm{i}}$; While stopping criteria is false do; Compute inertia weight $(\omega)$ if it is not a constant

Repeat for s times

Repeat for d times

update $\mathrm{v}_{\mathrm{i}}$ for particle; validate for velocity boundaries

If $\mathrm{v}_{\mathrm{i}}^{\mathrm{j}}<\mathrm{v}_{\text {min }} ; \mathrm{v}_{\mathrm{i}}^{\mathrm{j}} \leftarrow \mathrm{v}_{\min }$

else if $\mathrm{v}_{\mathrm{i}}^{\mathrm{j}}>\mathrm{v}_{\max } ; \mathrm{v}_{\mathrm{i}}^{\mathrm{j}} \leftarrow \mathrm{v}_{\max }$

end if

update $\mathrm{x}_{\mathrm{i}}$ for particle ; validate for position boundaries

If $x_{i}{ }^{j}<x_{\text {min }} ; x_{i}^{j} \leftarrow x_{\text {min }}$

else if $x_{i}^{j}>x_{\max } ; x_{i}^{j} \leftarrow x_{\max }$

end if

compute $\mathrm{f}\left(\mathrm{x}_{\mathrm{i}}\right)$

End Repeat for $\mathrm{d}$

compute $\mathrm{f}\left(\mathrm{x}_{\mathrm{i}}\right)$; obtain new pbest $\mathrm{i}_{\mathrm{i}}$

If $\mathrm{f}\left(\mathrm{x}_{\mathrm{i}}\right)<\mathrm{f}\left(\right.$ pbest $\left._{\mathrm{i}}\right)$ then pbest $\mathrm{i}_{\mathrm{i}} \leftarrow \mathrm{x}_{\mathrm{i}}$; If $\mathrm{f}\left(\mathrm{x}_{\mathrm{i}}\right)<\mathrm{f}$ (gbest) then

gbest $\leftarrow \mathrm{x}_{\mathrm{i}} ; \mathrm{f}($ gbest $) \leftarrow \mathrm{f}\left(\mathrm{x}_{\mathrm{i}}\right)$

end if

End Repeat for $\mathrm{s}$

End while

$\mathrm{x}^{*} \leftarrow$ gbest; $\mathrm{f}^{*} \leftarrow \mathrm{f}$ (gbest)

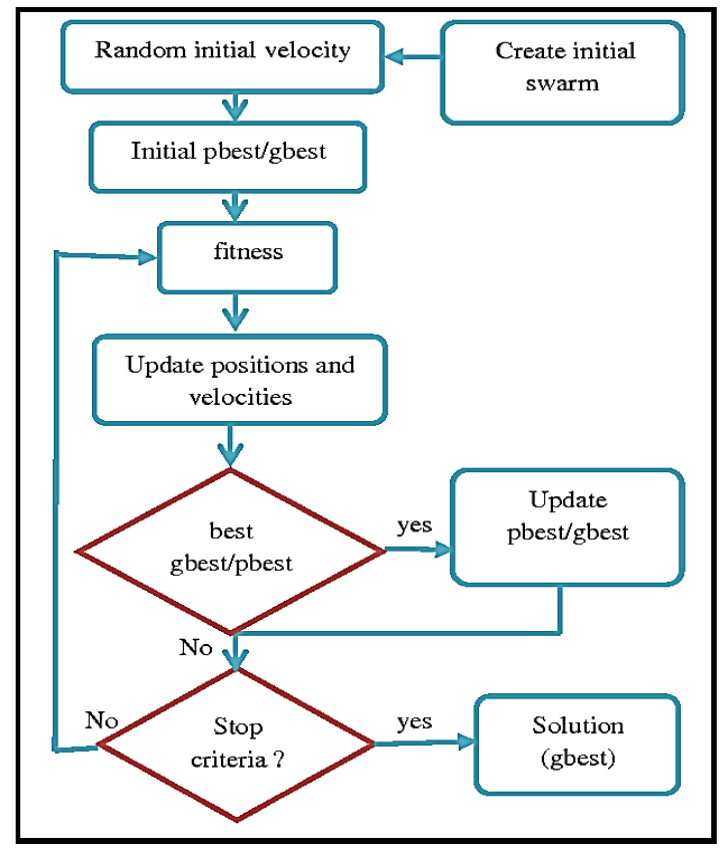

Figure 14. PSO algorithm execution procedure for the welding parameter optimization 
The PSO parameters chosen for optimizing the welding parameters are number of birds (n) are 50, number of iterations $(\mathrm{N})$ is around100, learning factors ( 1 and $\mathrm{c} 2$ ) are usually taken as 2 . The fitness function considered for PSO training are minimization of bead width and reinforcement and maximization of the depth of penetration. The weightage for weld bead, reinforcement and depth of penetration are taken as $0.25,0.25$ and 0.5 respectively.
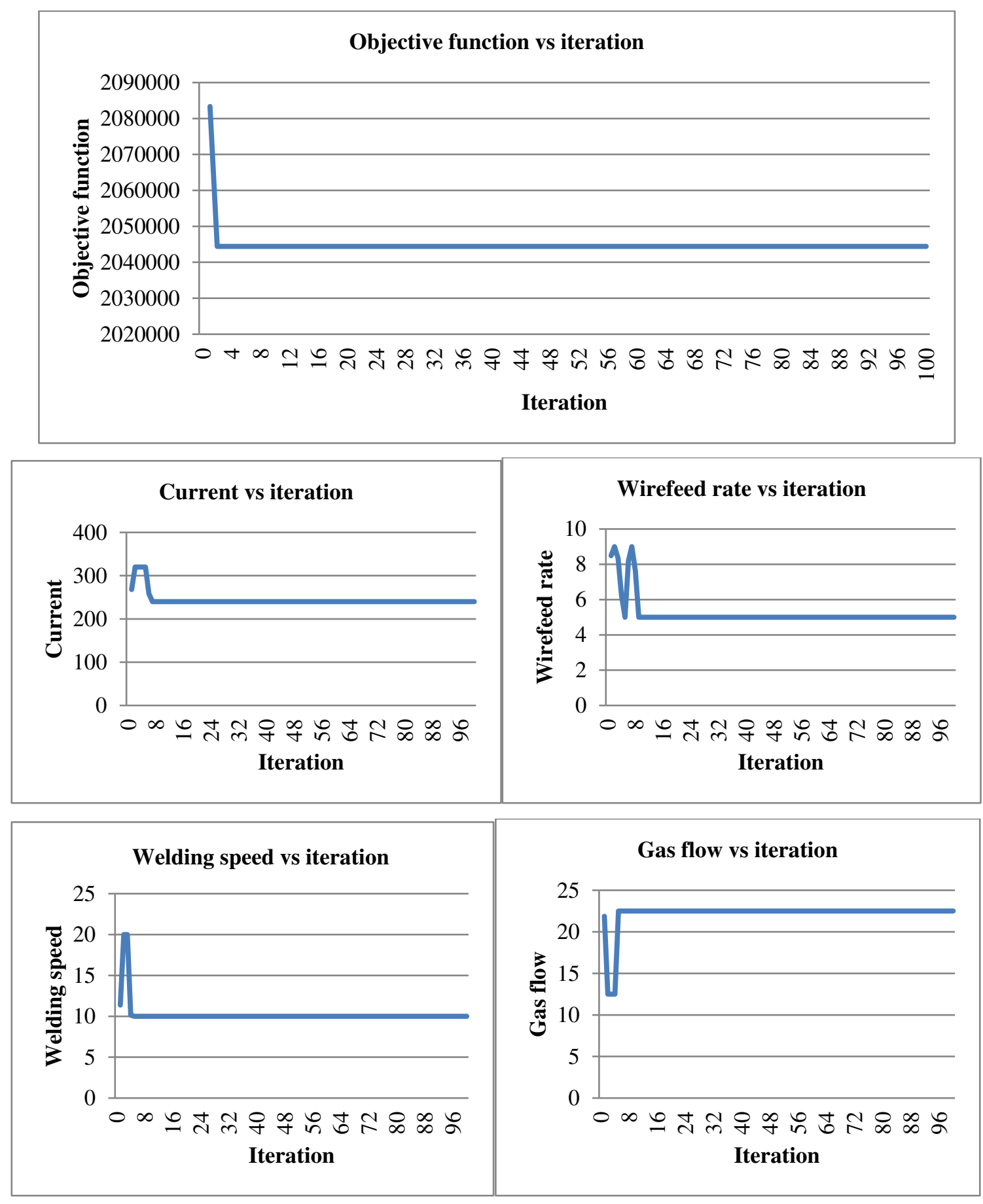

Figure 15. Convergence graph for welding input parameters using PSO algorithm 
Figure 15 shows the plot between the input parameters such as current (C), wire feed rate (FR), welding speed (WS) and gas flow (GF) versus number of iterations. The optimized values of input parameters for the desired welding profile are tabulated in Table 14.

Table 14 Optimized input parameters using PSO algorithm

\begin{tabular}{|c|c|c|c|c|c|c|c|c|}
\hline BH & DOP & BW & HD & TS & C & FR & WS & GF \\
\hline 1.0228 & 5.136 & 4.258 & 280.94 & 307.51 & 240 & 5 & 10 & 22.5 \\
\hline
\end{tabular}

\subsection{FIREFLY ALGORITHM}

The flashing characteristics of fireflies can idealize to develop firefly inspired algorithms. For simplicity in describing the Firefly Algorithm (FA), use the following three idealized rules: 1) All fireflies are unisex so that one firefly will be attracted to other fireflies 2) Attractiveness is proportional to their brightness, thus for any two flashing fireflies, the less brighter one will move towards the brighter one. The attractiveness is proportional to the brightness and they both decrease as their distance increases. If there is no brighter one than a particular firefly, it will move randomly. 3) The brightness of a firefly is affected or determined by the landscape of the objective function. For a maximization problem, the brightness can simply be proportional to the value of the objective function. Based on these three rules, the basic steps of the firefly algorithm (FA) can be summarized as the pseudo code as follows

Objective function $\mathrm{f}(\mathrm{x})$,

$$
\mathrm{x}=\left(\mathrm{x}_{1}, \ldots, \mathrm{x}_{\mathrm{d}}\right)^{\mathrm{T}}
$$

Generate initial population of fireflies

$\mathrm{x}_{\mathrm{i}}(\mathrm{i}=1,2, \ldots, \mathrm{n})$ Light intensity $\mathrm{I}_{\mathrm{i}}$ at $\mathrm{x}_{\mathrm{i}}$ is determined by $\mathrm{f}\left(\mathrm{x}_{\mathrm{i}}\right)$

Define light absorption coefficient $\gamma$ while $(\mathrm{t}<$ Max Generation)

for $\mathrm{i}=1: \mathrm{n}$ all $\mathrm{n}$ fireflies

for $\mathrm{j}=1: \mathrm{i}$ all $\mathrm{n}$ fireflies

if $\left(\mathrm{I}_{\mathrm{j}}>\mathrm{I}_{\mathrm{i}}\right)$, Move firefly $\mathrm{i}$ towards $\mathrm{j}$ in d-dimension;

end if , Attractiveness varies with distance $r$ via $\exp [-\gamma r]$

Evaluate new solutions and update light

Intensity end for $\mathrm{j}$;

end for I;

Rank the fireflies and find the current best end while

Post process results and visualization

For predicting each response, a quadratic model is generated. This empirical model is used to optimize the welding input parameters to achieve minimum bead width and bead height and maximize the depth of penetration. Simulation runs are carried out to optimize the firefly algorithm parameters by varying number of fireflies up to 1000 iterations as shown in Figure 16.

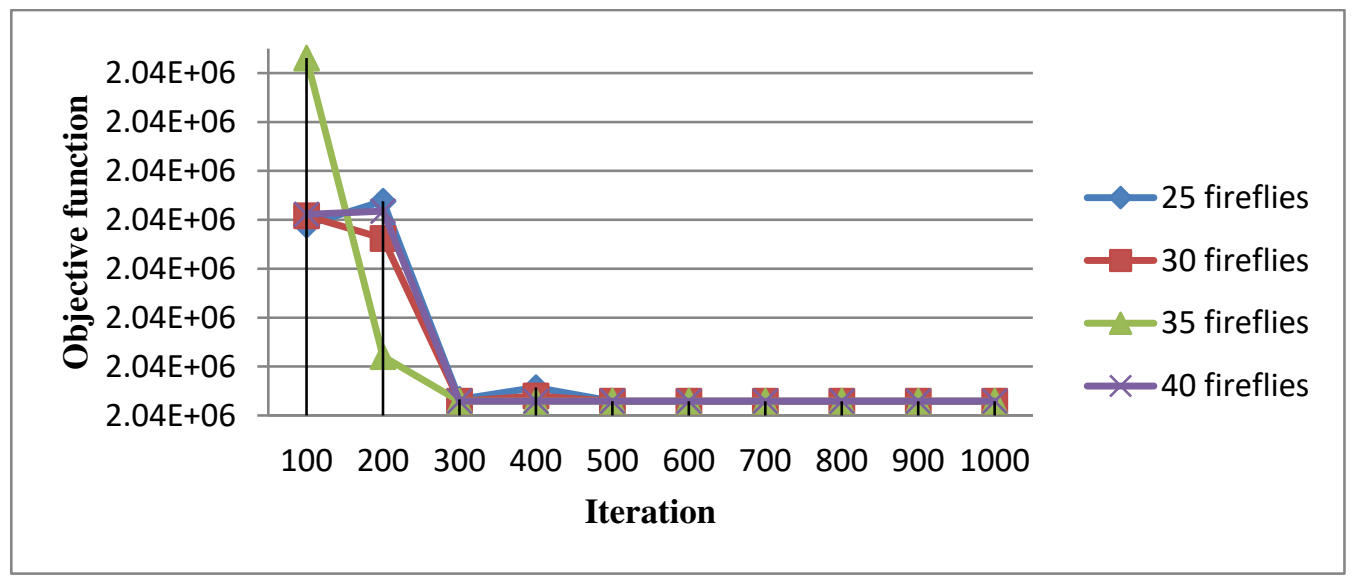

Figure 16. Convergence graph for optimizing number of fireflies 
The optimized firefly parameters are Number of fireflies (n) as 40, Number of iterations (N) as 1000, Randomization parameter $(\alpha)$ as 0.5 , Attractiveness $(\beta \mathrm{min})$ as 0.2 , and Light absorption coefficient $(\gamma)$ as 1 . The value of " $\alpha$ ” is chosen as 0.5 to reduce randomness and to increase the convergence. " $\beta$ min" is chosen as 0.2 , which varies with the absorption coefficient and source distance, which is the attractiveness of fireflies. Light absorption coefficient " $\gamma$ " is the absorption coefficient, which varies between 0 to $\infty$, which depends mainly on the light intensity of fireflies. With the obtained firefly parameters, the input parameters are optimized and shown in Figure 16.
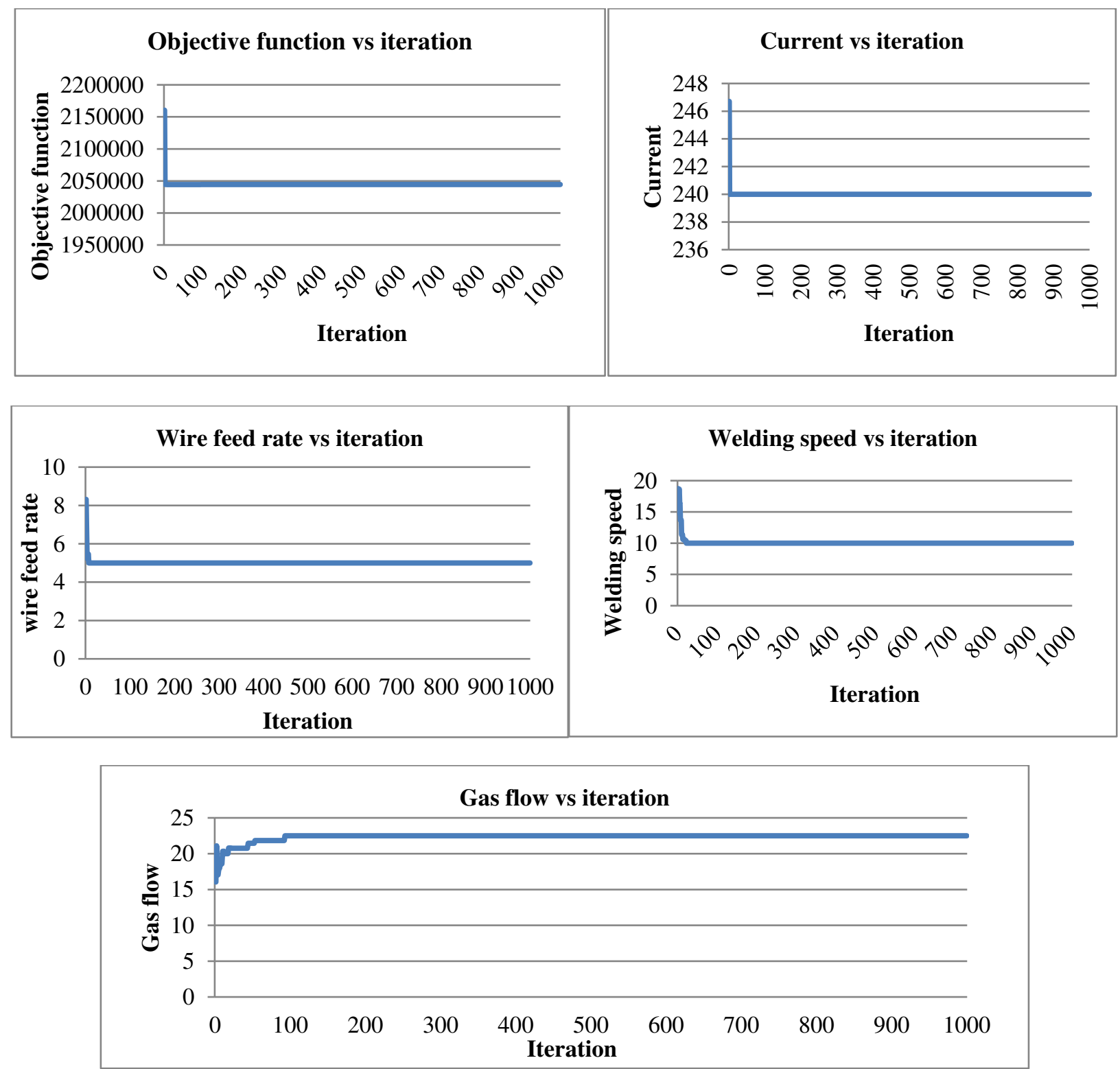

Figure 16. Convergence graph for welding input parameters using Firefly algorithm

The obtained results reveal that initially the value of current, wire feed rate, welding speed and gas flow starts at a random value. But when the iteration progress, it gets settled to the optimized value by increasing number of iterations. Table 15 shows the optimized values of welding input parameters and it is similar to the results of PSO algorithm. 
Table 15. Optimized input parameters using Firefly algorithm

\begin{tabular}{|c|c|c|c|c|c|c|c|c|}
\hline BH & DOP & BW & HD & TS & C & FR & WS & GF \\
\hline 1.0228 & 5.136 & 4.258 & 280.94 & 307.51 & 240 & 5 & 10 & 22.5 \\
\hline
\end{tabular}

On comparing the optimized results obtained through PSO and firefly algorithms, it is confirmed that parametric coordination for all above-mentioned characteristics are similar; however, PSO algorithm reached the better optimal values in very fewer iterations as compared to firefly algorithm. As a final analysis, the PSO algorithm is computationally more efficient on comparing with firefly algorithm.

\subsection{CONFIRMATORY TEST FOR MULTI-RESPONSE OPTIMIZATION}

The confirmation test is carried out by considering the new set of process parameters using the optimized input parameters obtained from PSO and Firefly algorithm. The welding run is performed and bead profile geometry Hardness and Tensile strength is measured and average values of three experimented results are presented in Table 16.

Table 16. Confirmation test results of multi-response optimization

\begin{tabular}{|c|c|c|c|c|}
\hline Sl.No & Parameters & $\begin{array}{c}\text { Optimized parameters with predicted } \\
\text { values }\end{array}$ & $\begin{array}{c}\text { Experimentally } \\
\text { observed Values }\end{array}$ & $\begin{array}{c}\% \text { of } \\
\text { error }\end{array}$ \\
\hline 1 & Current & $240 \mathrm{Amp}$ & $240 \mathrm{Amp}$ & - \\
\hline 2 & Feed Rate & $5 \mathrm{~m} / \mathrm{min}$ & $5 \mathrm{~m} / \mathrm{min}$ & - \\
\hline 3 & Welding Speed & $10 \mathrm{~mm} / \mathrm{sec}$ & $10 \mathrm{~mm} / \mathrm{sec}$ & - \\
\hline 4 & Gas flow & $22.5 \mathrm{l} / \mathrm{min}$ & $22.5 \mathrm{lmin}$ & - \\
\hline 5 & Bead Height & $1.0228 \mathrm{~mm}$ & $5.0113 \mathrm{~mm}$ & 1.124 \\
\hline 6 & Depth of Penetration & $5.236 \mathrm{~mm}$ & $4.196 \mathrm{~mm}$ & 3.972 \\
\hline 7 & Bead Width & $4.258 \mathrm{~mm}$ & $281.87 \mathrm{VHN}$ & -0.331 \\
\hline 8 & Hardness & $280.94 \mathrm{VHN}$ & $307.03 \mathrm{~N} / \mathrm{mm} 2$ & 0.156 \\
\hline 9 & Tensile Strength & $307.51 \mathrm{~N} / \mathrm{mm} 2$ & & \\
\hline
\end{tabular}

From the Table 16, it is clearly seen that the experimental results of bead profiles have come closer to the predicted values and also the error is negligible. Further, it is confirmed that the percentage error is less than $4 \%$ i.e. percentage error is within the acceptable range.

\subsection{SEM OBSERVATION OF THE TENSILE FRACTURES}

The tensile fractures of the welded joint are examined by Scanning Electron Microscopic (SEM) as shown in Figure 17. The fracture width along the horizontal direction for both joints is noticeably small and the fracture size along the direction perpendicular to the plate surface for both joints is reasonably seems to be large. The fracture of the butt joint consists of large quantities of dimples. A large quantity of columnar grain boundaries distributed along the direction perpendicular to the tensile loading direction in the welding joint. 

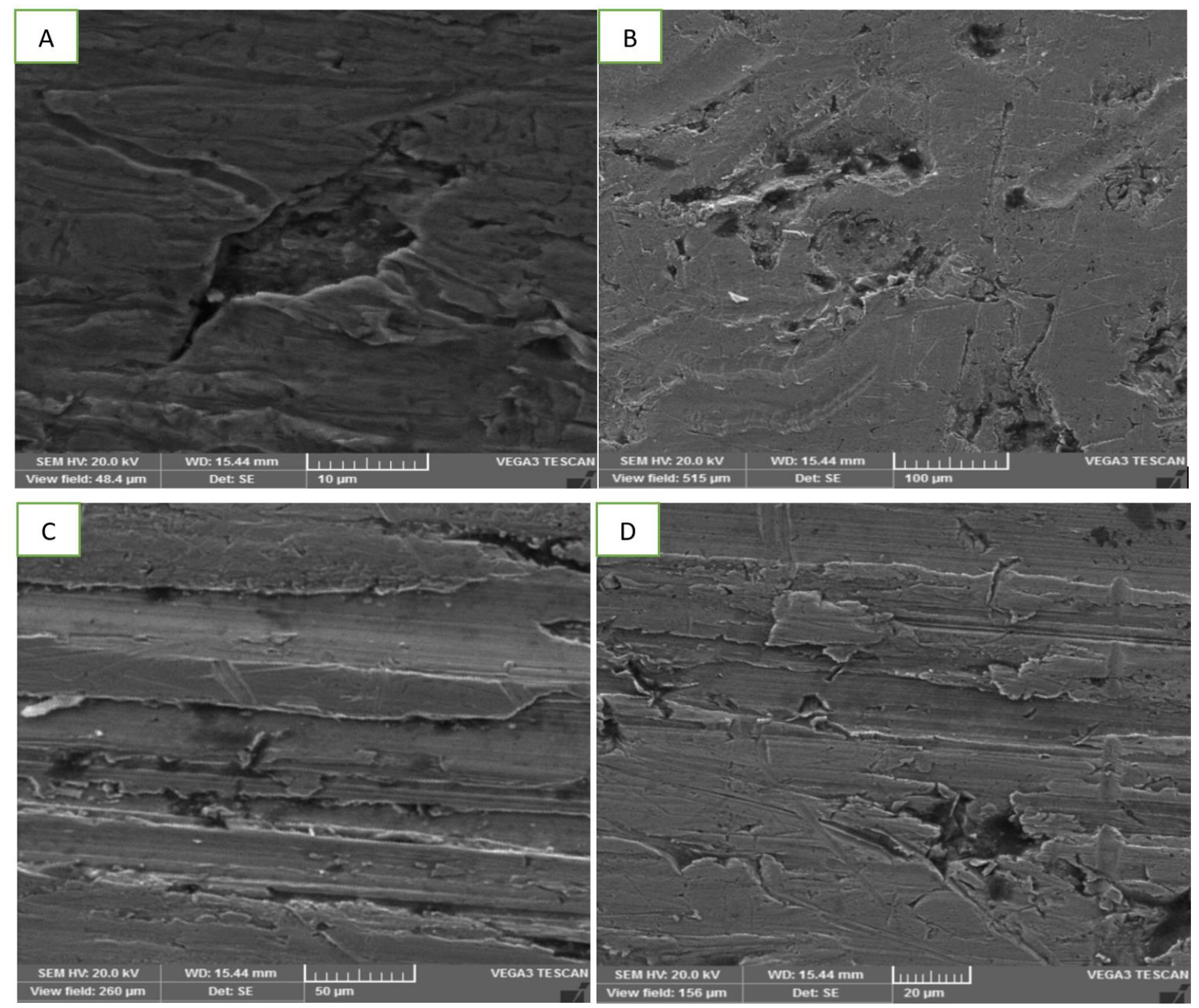

Figure 17. SEM observations of the tensile fractures of the welded joint

Investigation of the tensile fracture surfaces of the base and AISI: 430 stainless steel specimens is finished at low magnification mainly to identify the side of the welding to analyse the advancing or retreating level where the fracture mainly oriented. The fracture surfaces of tensile weld joints are normally categorized by a bimodal distribution of large voids, associated with the particle reinforcement as shown in Figure 17 (A\&B) and large dimples associated with the ductile failure of the ferrite stainless steel material as shown in Figure 17 (C\&D). Further, no indication of transformation in the particle-matrix metal interaction induced by the GMAW process is inferred from these SEM analyses.

\section{CONCLUSIONS}

The welding parameters for the material Ferritic Stainless Steel 430 using IRB 1410 ARC welding Robot is optimized using Response Surface Methodology. In the present work, around 31 experiments are acknowledged using RSM method with 2 replicates. The following results are inferred from both single and multi-response optimization techniques evalautions:

$\square$ The optimum welding input parameters obtained by RSM are current (320 Amps), wire feed rate ( $9 \mathrm{~m} / \mathrm{min}$ ), Welding speed $(10 \mathrm{~mm} / \mathrm{sec})$ and gas flow $(12.5 \mathrm{l} / \mathrm{m})$. For these values, the optimal output parameters obtained by single response optimization are minimum bead height $(1.802 \mathrm{~mm})$, minimum bead width $(4.287 \mathrm{~mm})$ and maximum depth of penetration $(5.207 \mathrm{~mm})$. 
Similarly, the optimum welding input parameters obtained by PSO and FA are current (240 Amps), wire feed rate $(5 \mathrm{~m} / \mathrm{min})$, welding speed $(10 \mathrm{~mm} / \mathrm{sec})$ and gas flow $(22.5 \mathrm{l} / \mathrm{m})$. For these values, the multi response optimization techniques provide the minimum bead height as $1.0228 \mathrm{~mm}$, minimum bead width as $4.258 \mathrm{~mm}$ and maximum depth of penetration as $5.236 \mathrm{~mm}$.

On comparing the result of RSM and metaheuristic algorithms, the result obtained through the meta heuristic algorithm is better. Although the optimized output values obtained from the PSO and FA algorithm are similar, the PSO converges quicker than FA with minimum number of iterations. Hence the PSO is more computationally efficient than FA and RSM.

To validate the predicted results with optimized process parameters, confirmation test for both single and multiresponse optimization reveal that the computed errors are found to be less than $5 \%$ (i.e. more sufficient).

By the current work on combined experimental and optimization research, it has been understood that both PSO and Firefly algorithms have the capability to perform single as well as multi-objective optimization, particularly for Gas metal arc welding process. Hence, the proposed RSM and meta heuristic optimization algorithm by integrating into the empirical model shows that the implemented optimization framework seems to be reliable and robust.

\section{DECLARATIONS}

Availability of data \& material: Not applicable.

Competing interests: There is no conflict of interests among the authors regarding the publication of this article. Funding: Not applicable.

Author's contribution: All authors have read and approved the manuscript.

Acknowledgement: Not applicable.

\section{REFERENCES}

1. Gerin, M., et al., Development and use of a welding process exposure matrix in a historical prospective study of lung cancer risk in European welders. Int J Epidemiol, 1993. 22 Suppl 2: p. S22-8.

2. Edme, J.L., et al., Assessment of biological chromium among stainless steel and mild steel welders in relation to welding processes. Int Arch Occup Environ Health, 1997. 70(4): p. 237-42.

3. Yu, I.J., et al., Recovery from manual metal arc-stainless steel welding-fume exposure induced lung fibrosis in Sprague-Dawley rats. Toxicol Lett, 2003. 143(3): p. 247-59.

4. Sorensen, A.R., et al., Risk of lung cancer according to mild steel and stainless steel welding. Scand J Work Environ Health, 2007. 33(5): p. 379-86.

5. Keane, M., et al., Hexavalent chromium content in stainless steel welding fumes is dependent on the welding process and shield gas type. J Environ Monit, 2009. 11(2): p. 418-24.

6. Keane, M., S. Stone, and B. Chen, Welding fumes from stainless steel gas metal arc processes contain multiple manganese chemical species. J Environ Monit, 2010. 12(5): p. 1133-40.

7. Erdely, A., et al., Inhalation exposure of gas-metal arc stainless steel welding fume increased atherosclerotic lesions in apolipoprotein E knockout mice. Toxicol Lett, 2011. 204(1): p. 12-6.

8. Lundin, M., et al., Adsorption and protein-induced metal release from chromium metal and stainless steel. J Colloid Interface Sci, 2012. 366(1): p. 155-64.

9. Hedberg, Y., et al., Surface-protein interactions on different stainless steel grades: effects of protein adsorption, surface changes and metal release. J Mater Sci Mater Med, 2013. 24(4): p. 1015-33.

10. Hwang, G., P. Podrzaj, and H. Hashimoto, Note: Resistance spot welding using a microgripper. Rev Sci Instrum, 2013. 84(10): p. 106105.

11. Brand, P., et al., Number size distribution of fine and ultrafine fume particles from various welding processes. Ann Occup Hyg, 2013. 57(3): p. 305-13.

12. Sriram, K., et al., Neurotoxicity following acute inhalation of aerosols generated during resistance spot weldbonding of carbon steel. Inhal Toxicol, 2014. 26(12): p. 720-32.

13. Afshari, A., et al., Development and characterization of a resistance spot welding aerosol generator and inhalation exposure system. Inhal Toxicol, 2014. 26(12): p. 708-19.

14.Zeidler-Erdely, P.C., et al., Effects of acute inhalation of aerosols generated during resistance spot welding with mild-steel on pulmonary, vascular and immune responses in rats. Inhal Toxicol, 2014. 26(12): p. 697-707.

15.Chan, K.W. and S.C. Tjong, Effect of Secondary Phase Precipitation on the Corrosion Behavior of Duplex Stainless Steels. Materials (Basel), 2014. 7(7): p. 5268-5304. 
16. Hsieh, C.C., et al., Evolution of microstructure and residual stress under various vibration modes in 304 stainless steel welds. ScientificWorldJournal, 2014. 2014: p. 895790.

17.Liu, J., et al., Ultrasonic test of resistance spot welds based on wavelet package analysis. Ultrasonics, 2015. 56: p. 557-65.

18. Cena, L.G., et al., A Field Study on the Respiratory Deposition of the Nano-Sized 8Fraction of Mild and Stainless Steel Welding Fume Metals. J Occup Environ Hyg, 2015. 12(10): p. 721-8.

19. Deng, D., et al., Microstructural Study of 17-4PH Stainless Steel after Plasma-Transferred Arc Welding. Materials (Basel), 2015. 8(2): p. 424-434.

20. Keane, M., et al., Profiling stainless steel welding processes to reduce fume emissions, hexavalent chromium emissions and operating costs in the workplace. J Occup Environ Hyg, 2016. 13(1): p. 1-8.

21.Wang, J., et al., Characterization of Particulate Fume and Oxides Emission from Stainless Steel Plasma Cutting. Ann Work Expo Health, 2017. 61(3): p. 311-320.

22. Kumar, S.R., et al., Investigation on Microstructural behavior and Mechanical Properties of plasma arc welded dissimilar butt joint of austenitic- ferritic stainless steels. Materials Today: Proceedings, 2018. 5(2, Part 2): p. 80088015.

23.Zhang, X., et al., Effect of Welding Current on Weld Formation, Microstructure, and Mechanical Properties in Resistance Spot Welding of CR590T/340Y Galvanized Dual Phase Steel. Materials (Basel), 2018. 11(11).

24.Zhao, Y., Y. Zhang, and X. Lai, Effect of Epoxy Adhesive on Nugget Formation in Resistance Welding of SAE1004/DP600/DP780 Steel Sheets. Materials (Basel), 2018. 11(10).

25. Taram, A., et al., Nondestructive testing of resistance spot welds using eddy current thermography. Appl Opt, 2018. 57(18): p. D63-D68. 
Figures

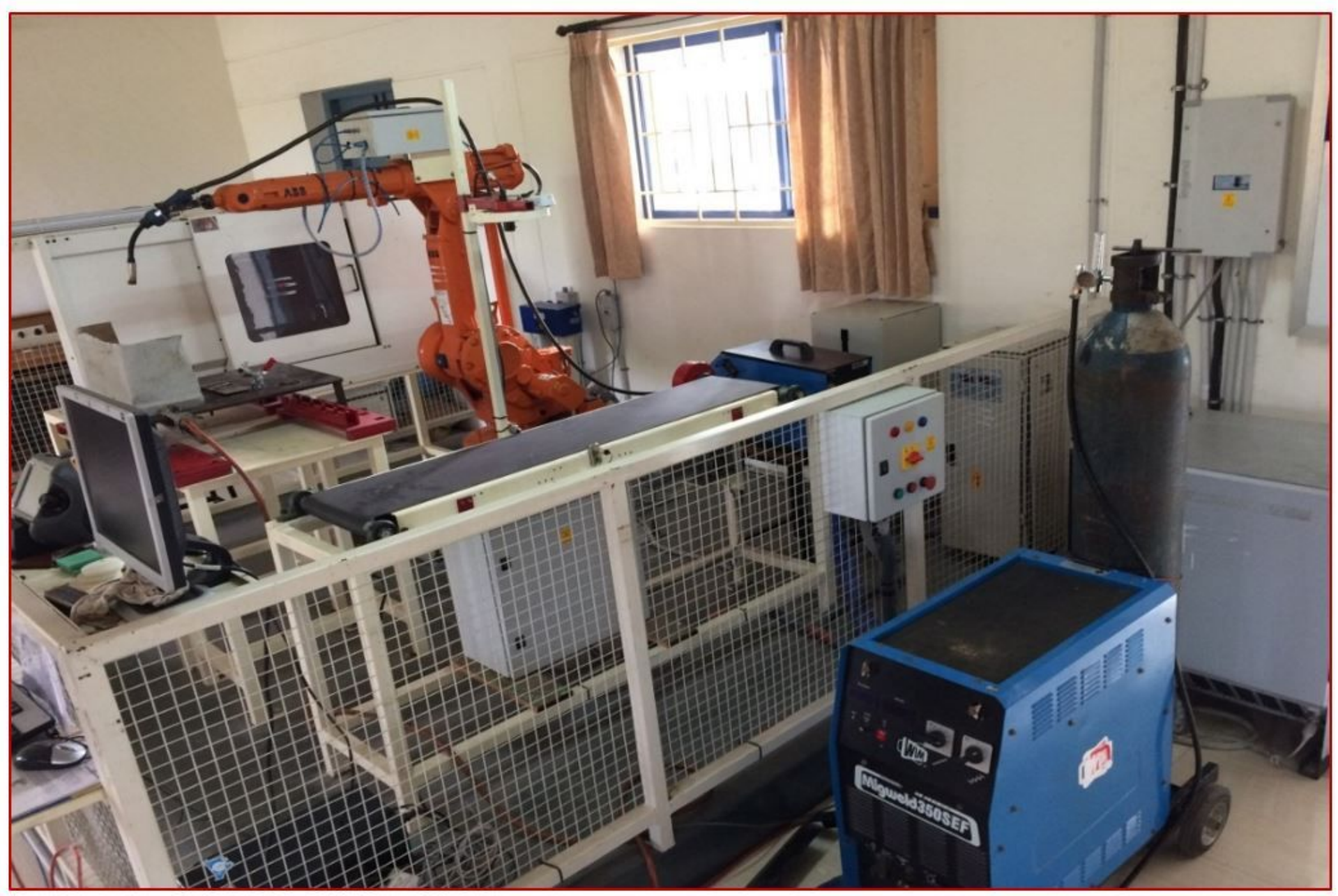

Figure 1

IRB 1410Arc Welding Robot 


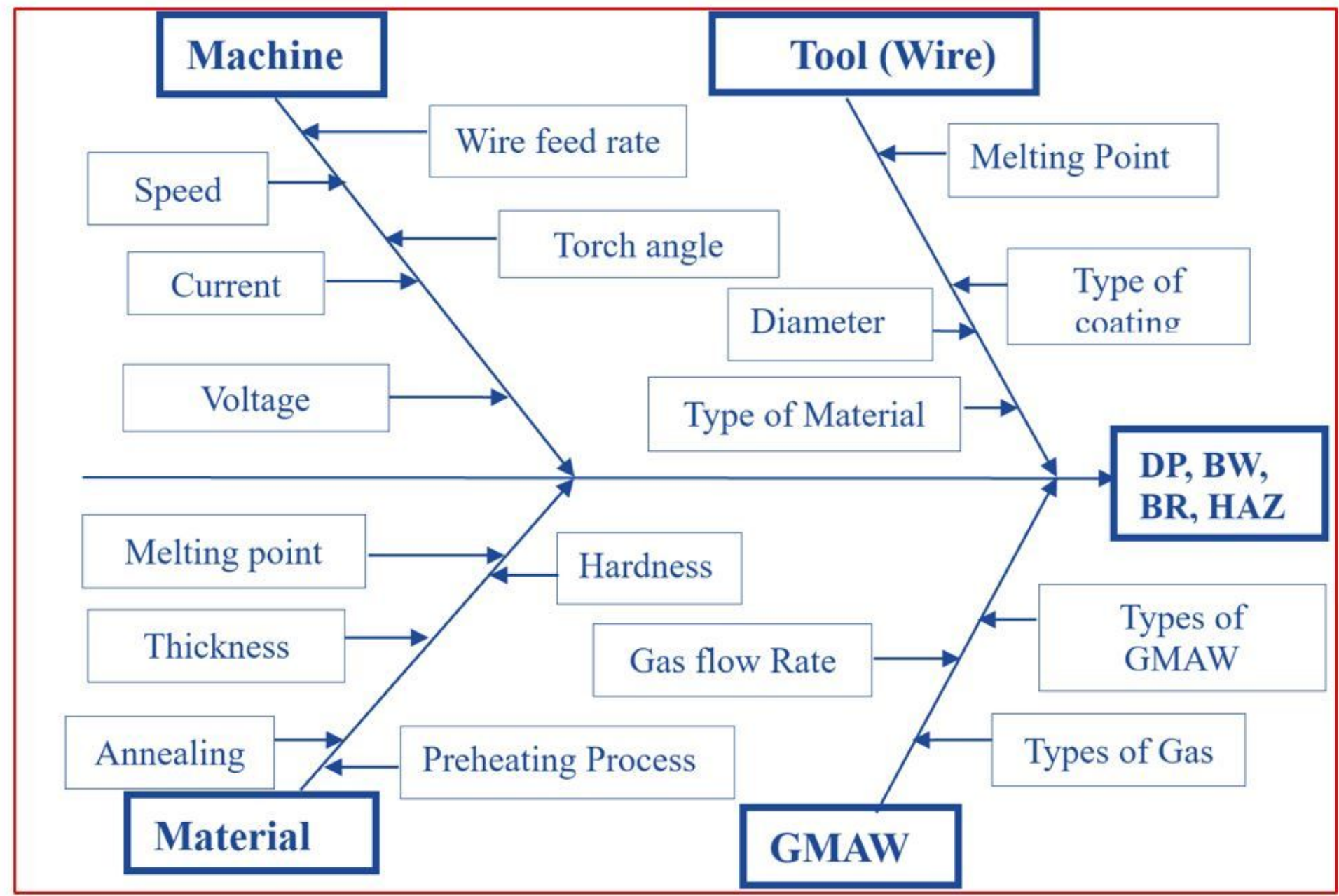

Figure 2

Cause and effect schematic of GMAW process

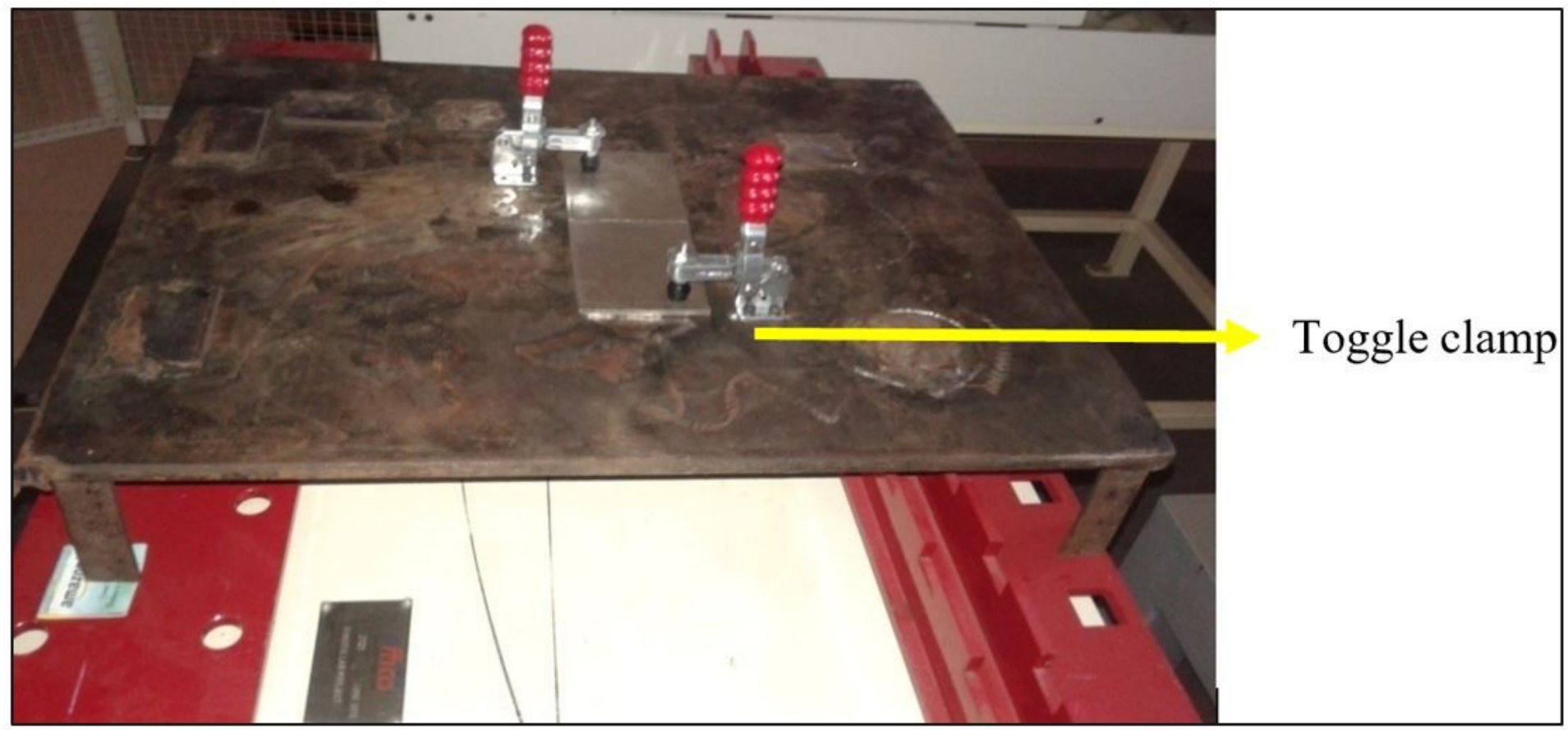


Figure 3

Fixture design taken for the present work

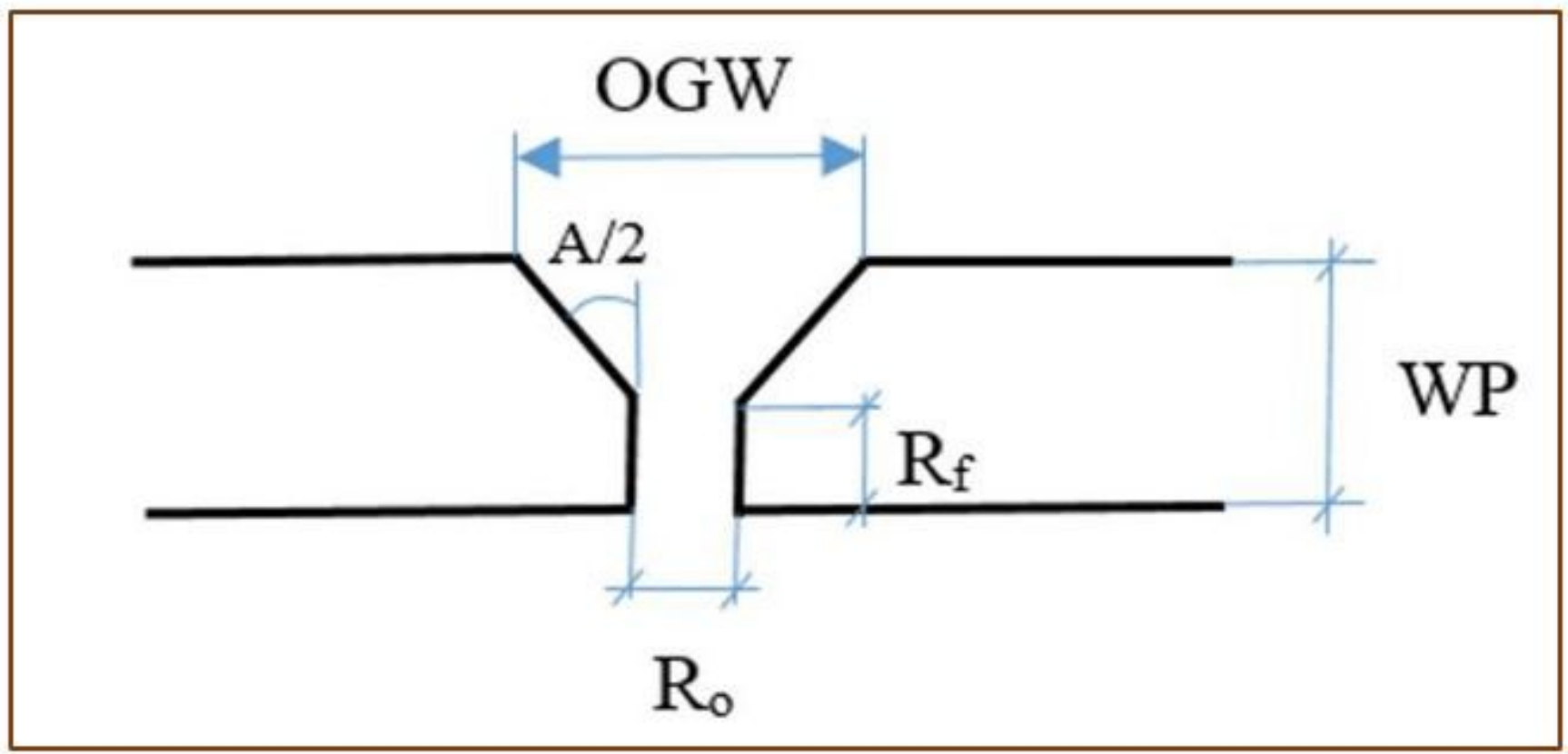

Figure 4

Joint edge specifications for GMAW of plates

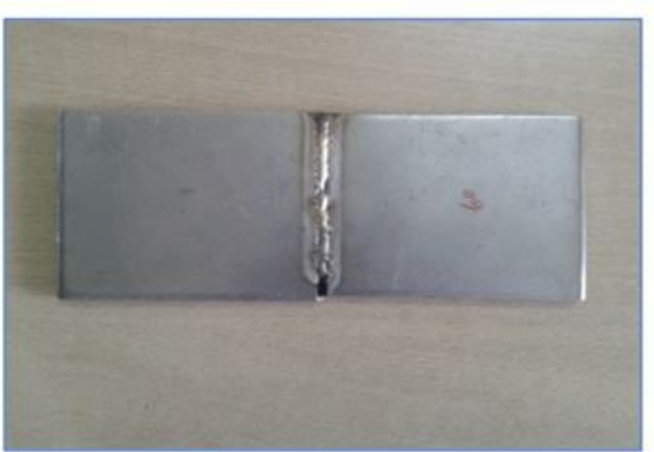

$60^{\circ}$ Groove Angle without gap

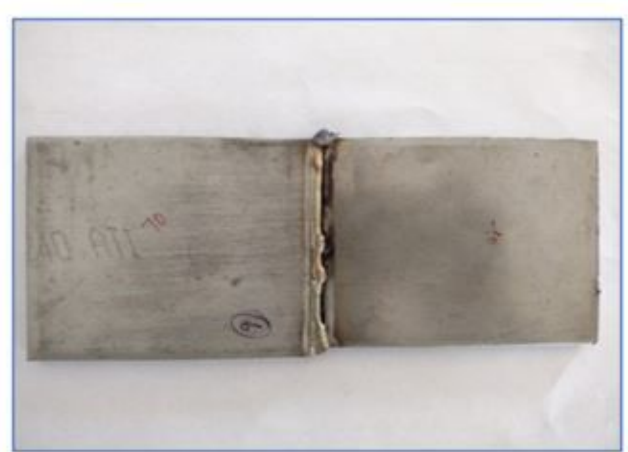

$60^{\circ}$ Groove Angle with $1 \mathrm{~mm}$ gap

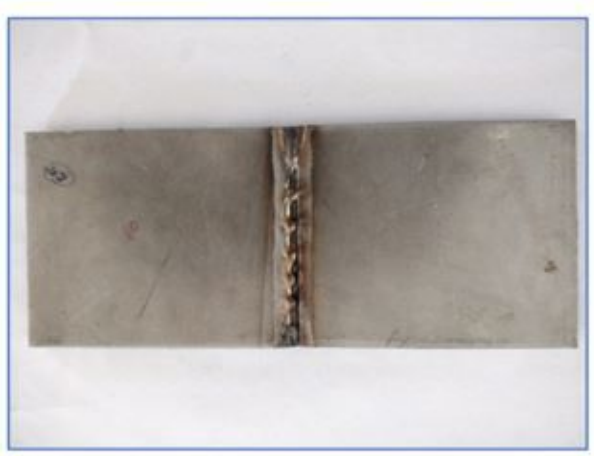

Groove Angle $70^{\circ}$

\section{Figure 5}

V-groove angles of the joints taken for experimentation trials 


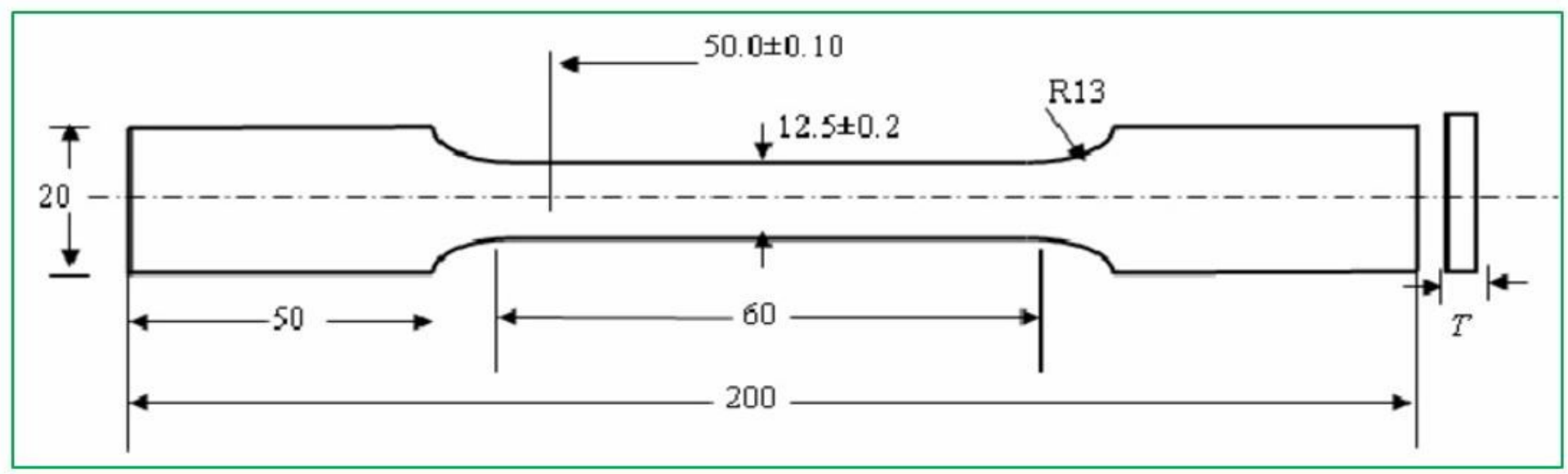

Figure 6

Tensile Standard dimensions

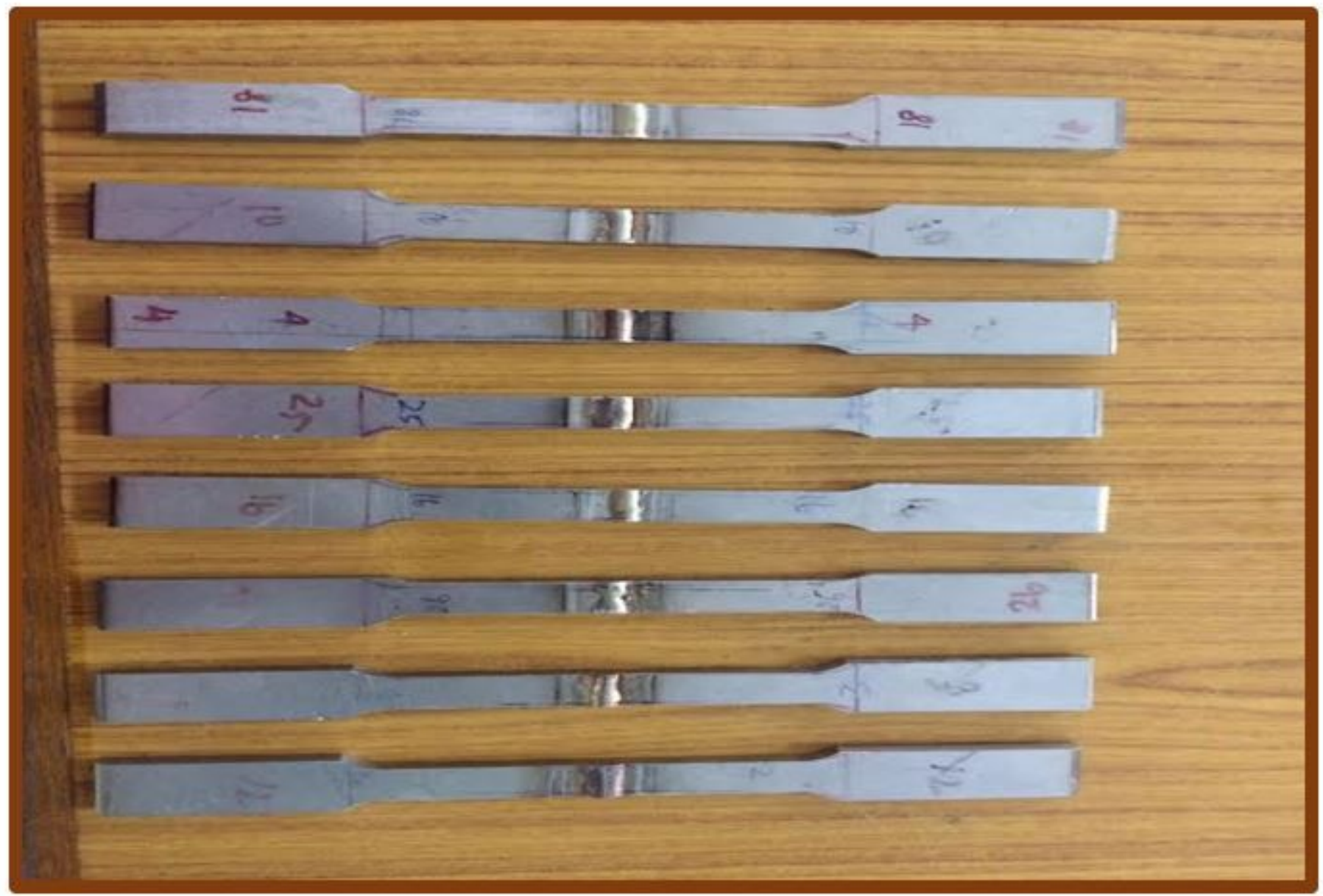

Figure 7

Dumb-bell shape 


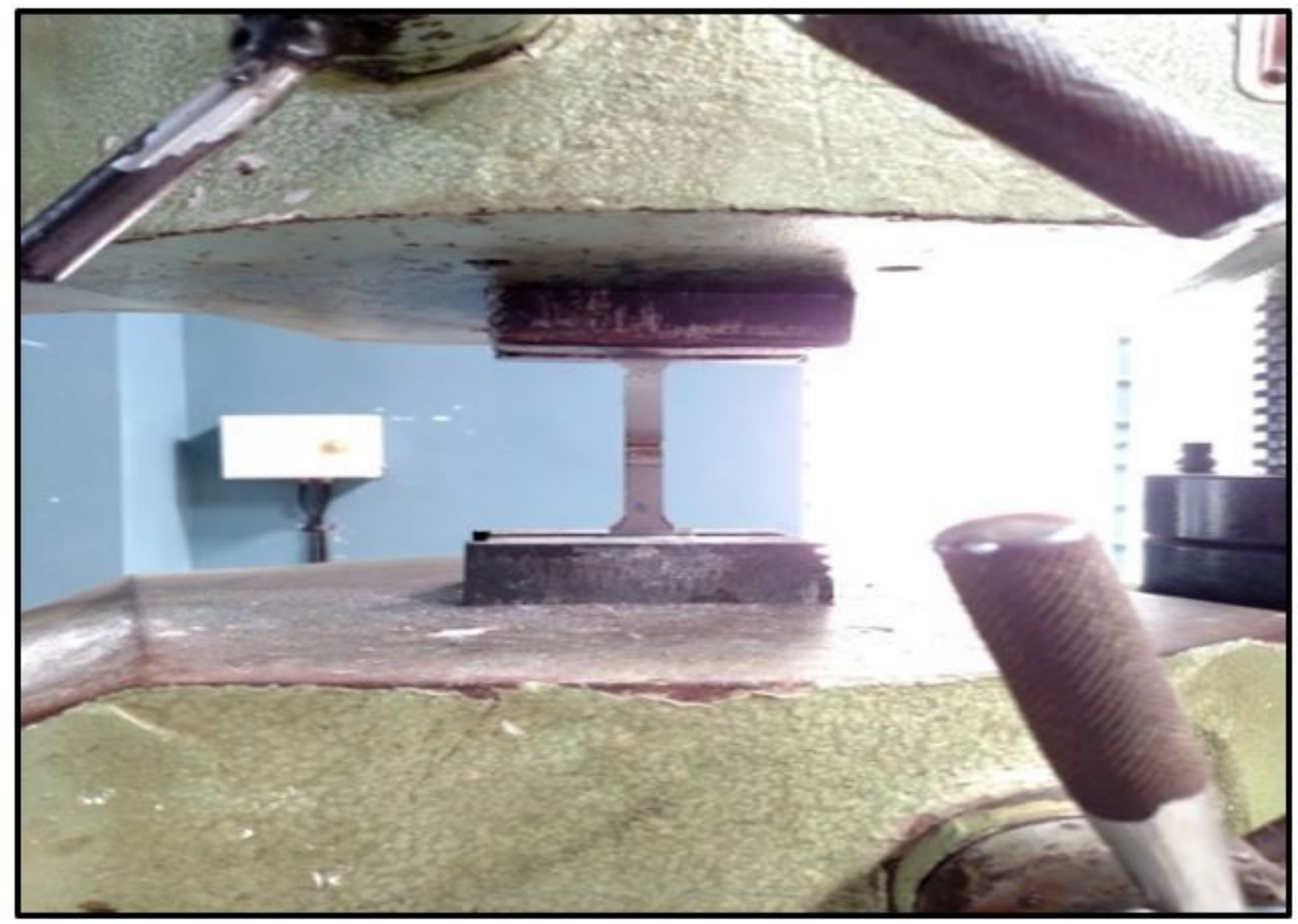

Figure 8

Universal Testing machine 


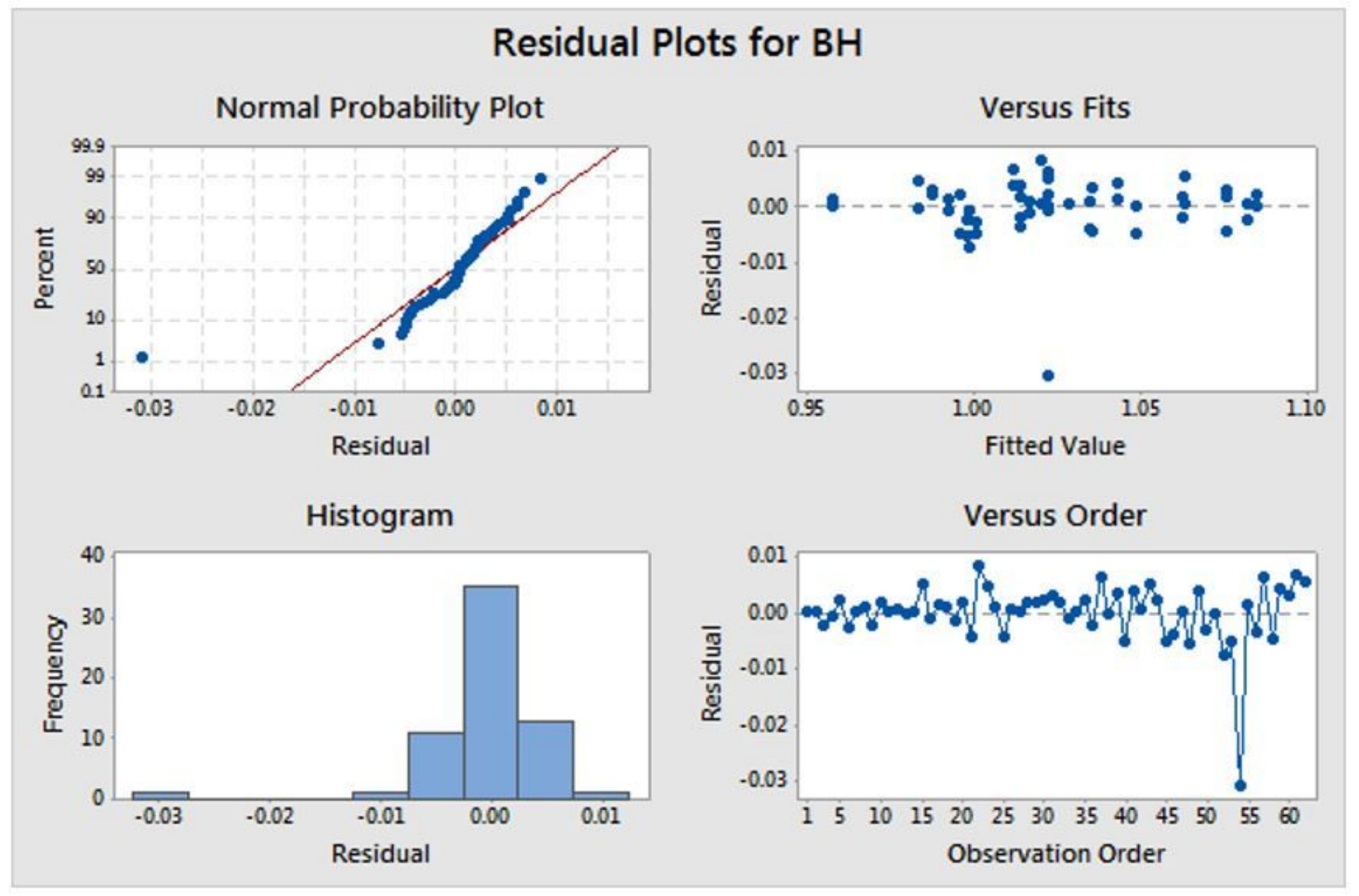

Figure 9

Obtained residual plot for the bead height parameter 


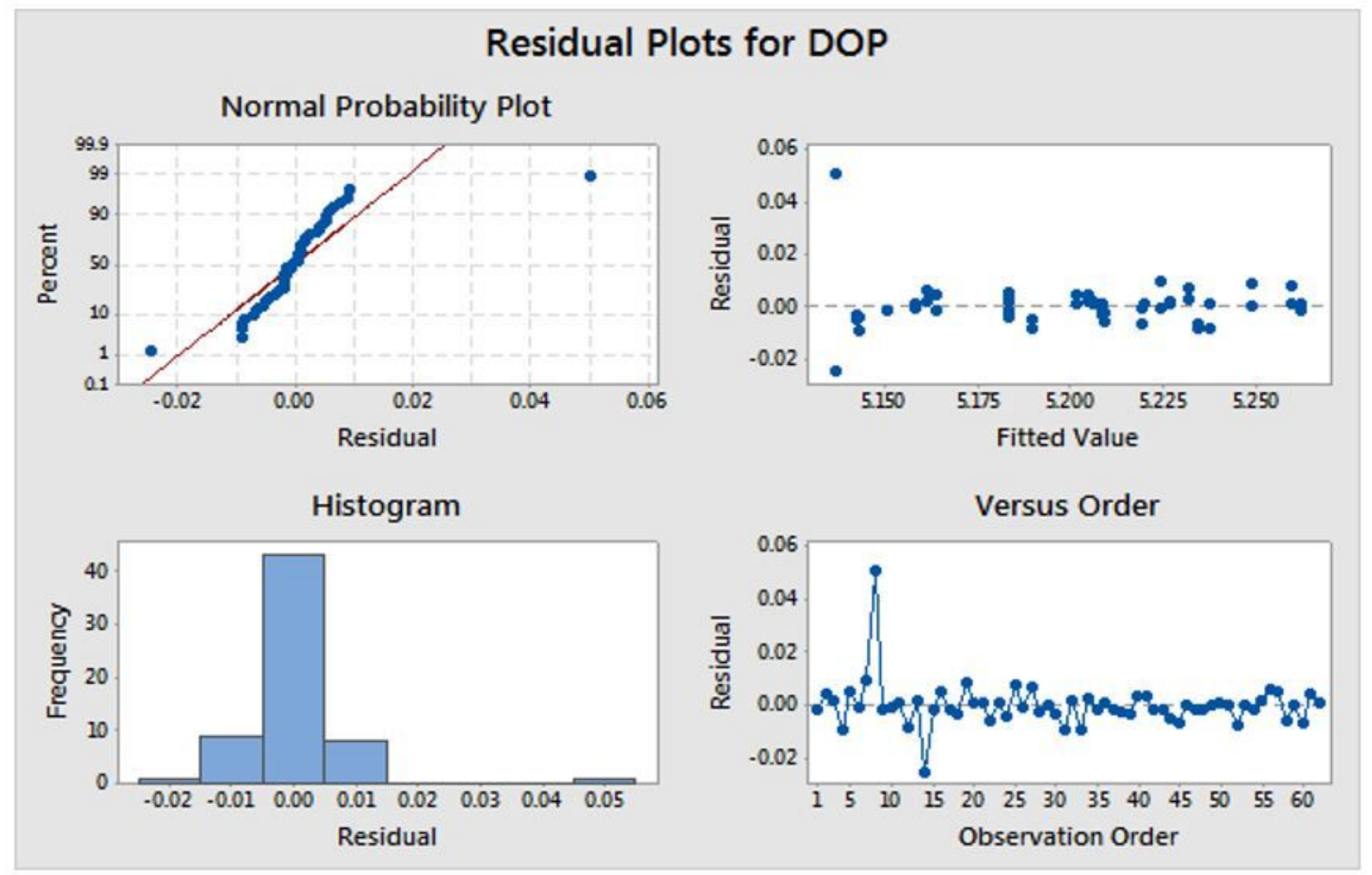

Figure 10

Residual plots of Depth of penetration 


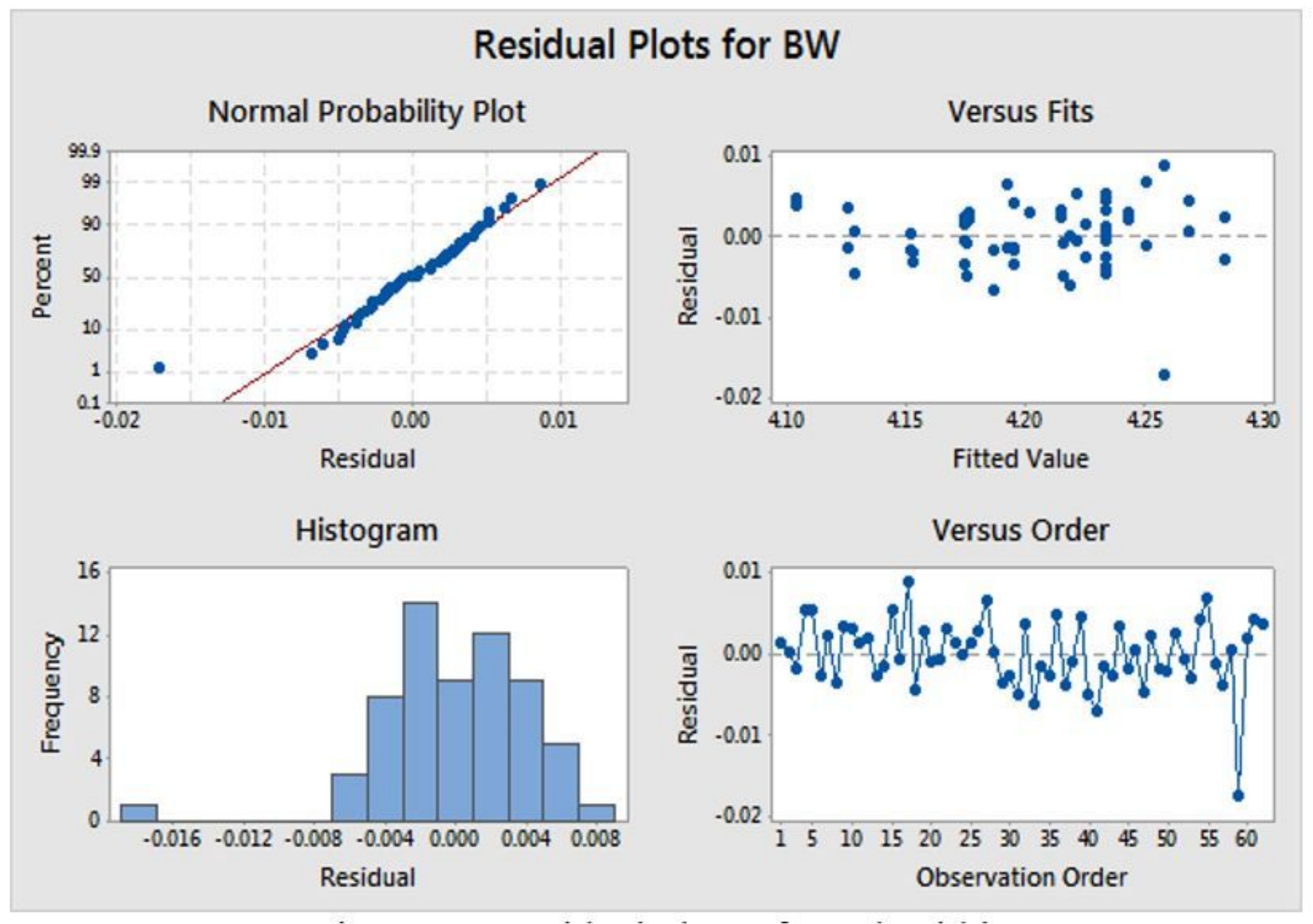

Figure 11

Residual plots of Bead Width 


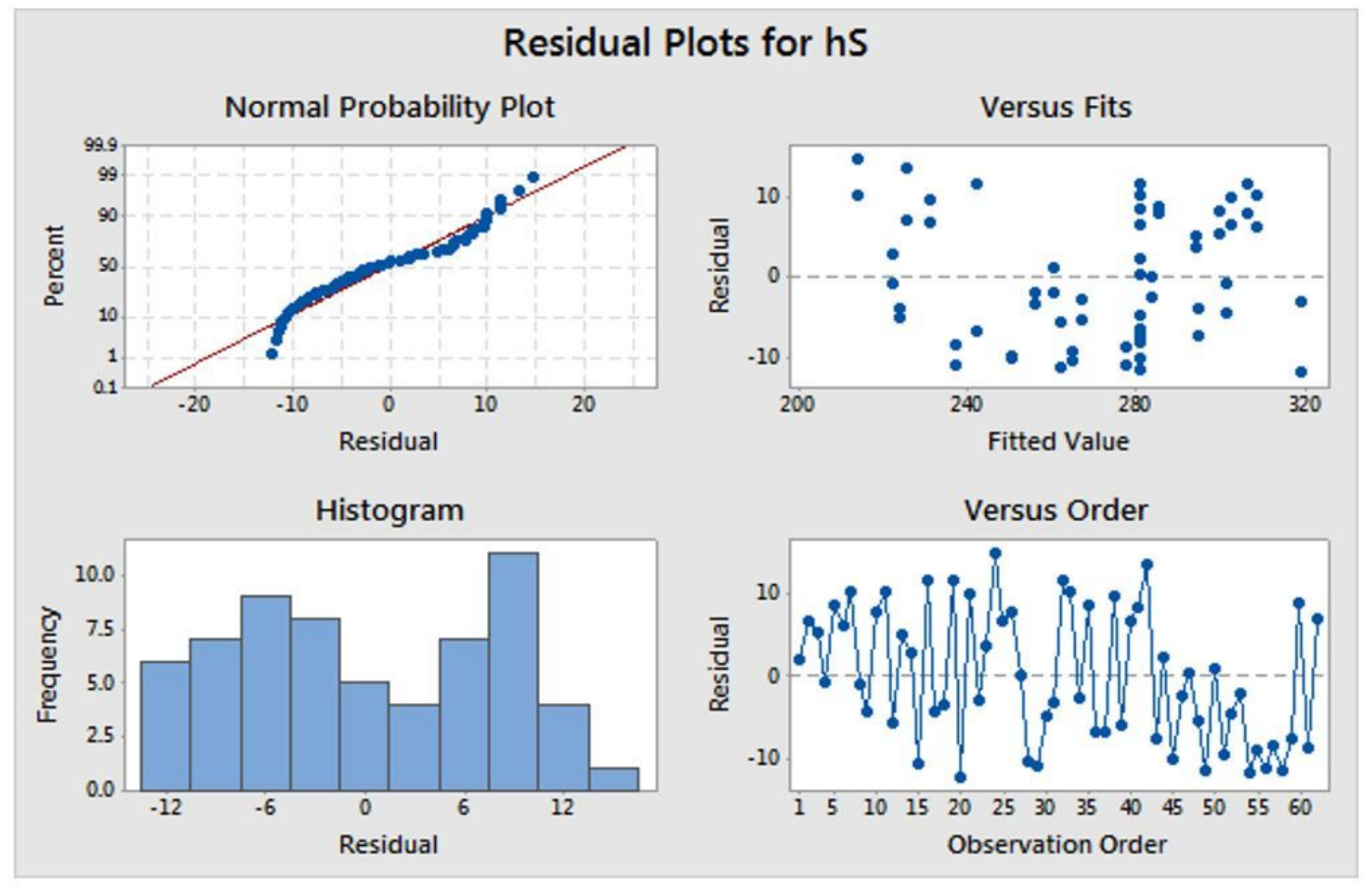

Figure 12

Residual plots of Hardness 


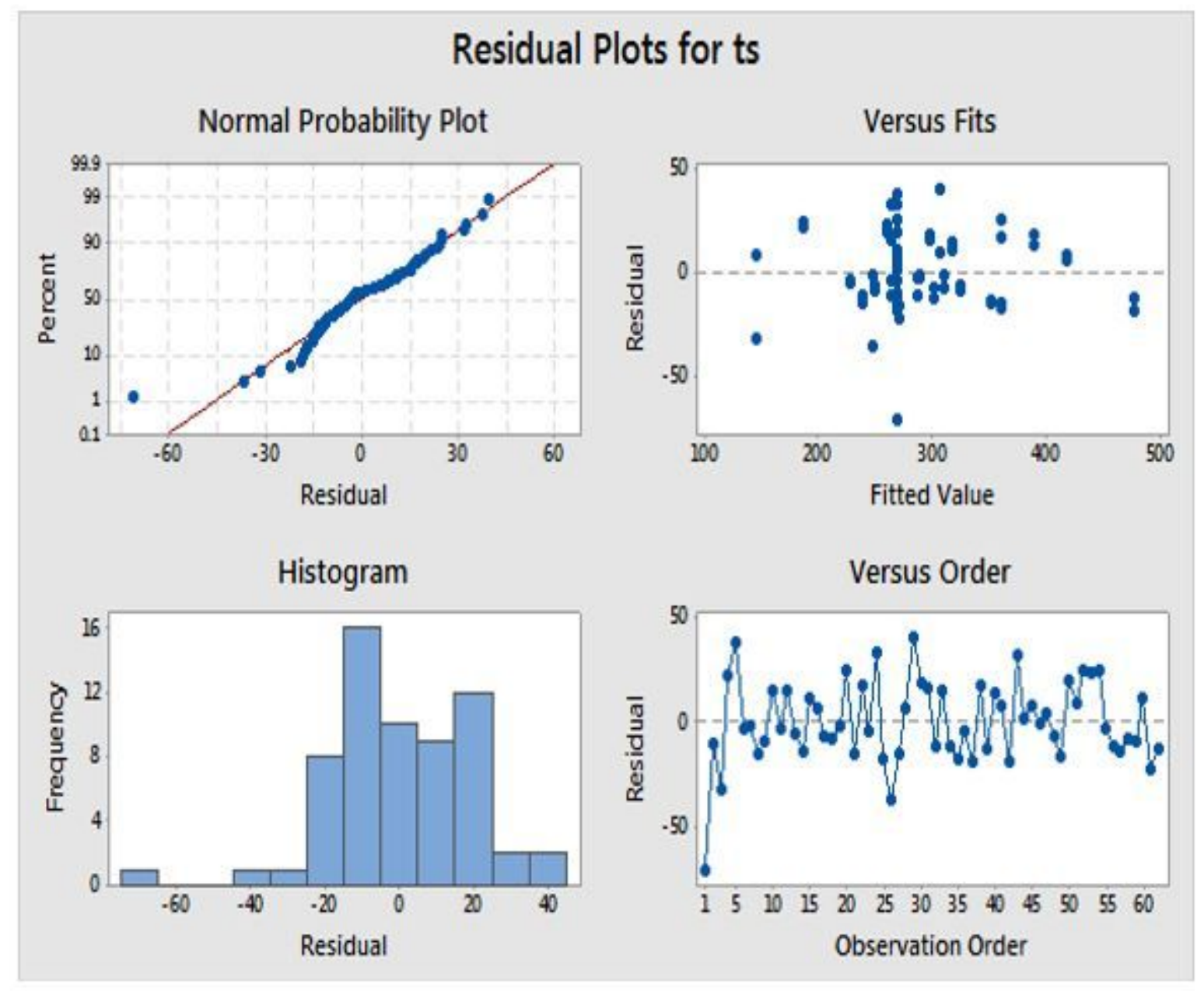

Figure 13

Residual plots of Tensile Strength 


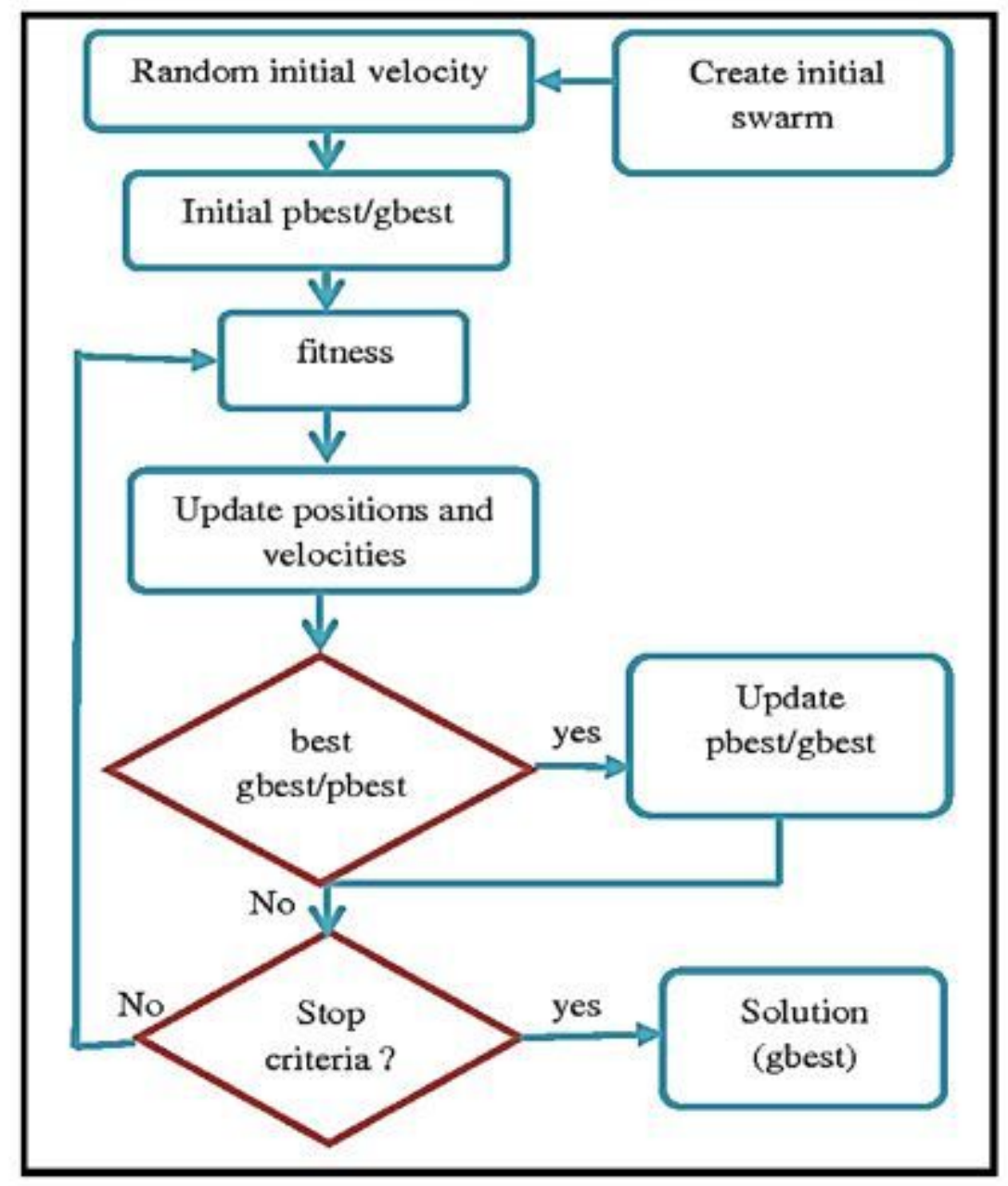

Figure 14

PSO algorithm execution procedure for the welding parameter optimization 

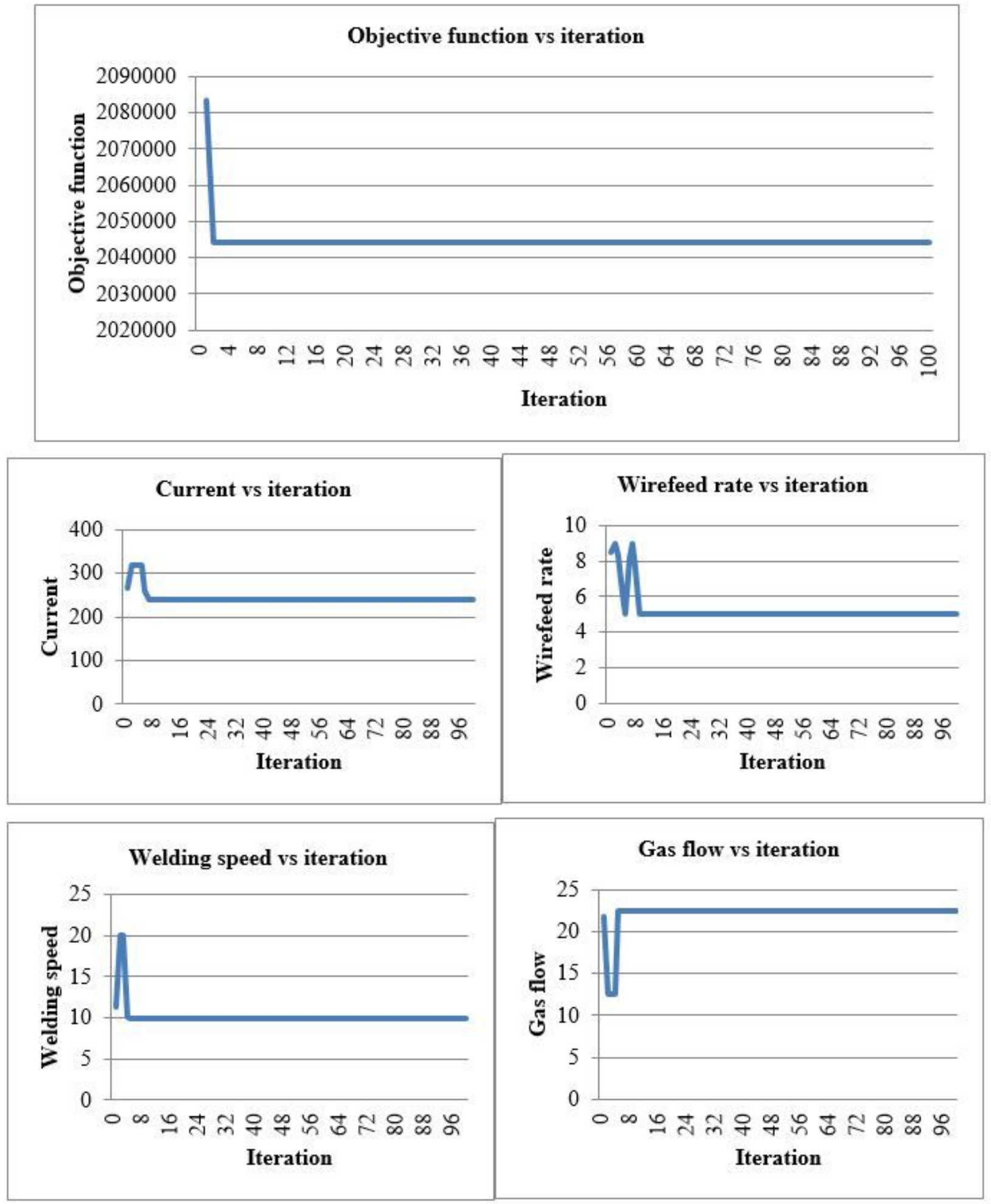

Figure 15

Convergence graph for welding input parameters using PSO algorithm 


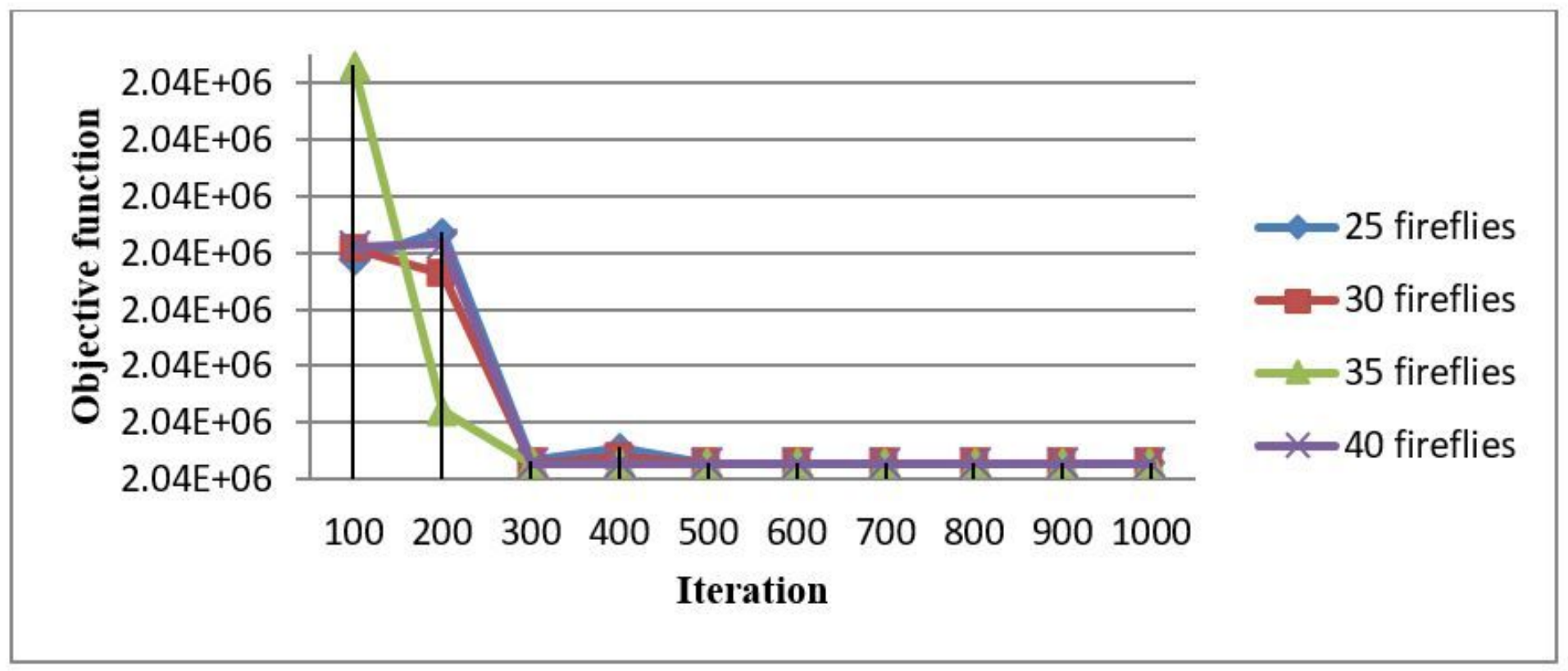

Figure 16

Convergence graph for optimizing number of fireflies 

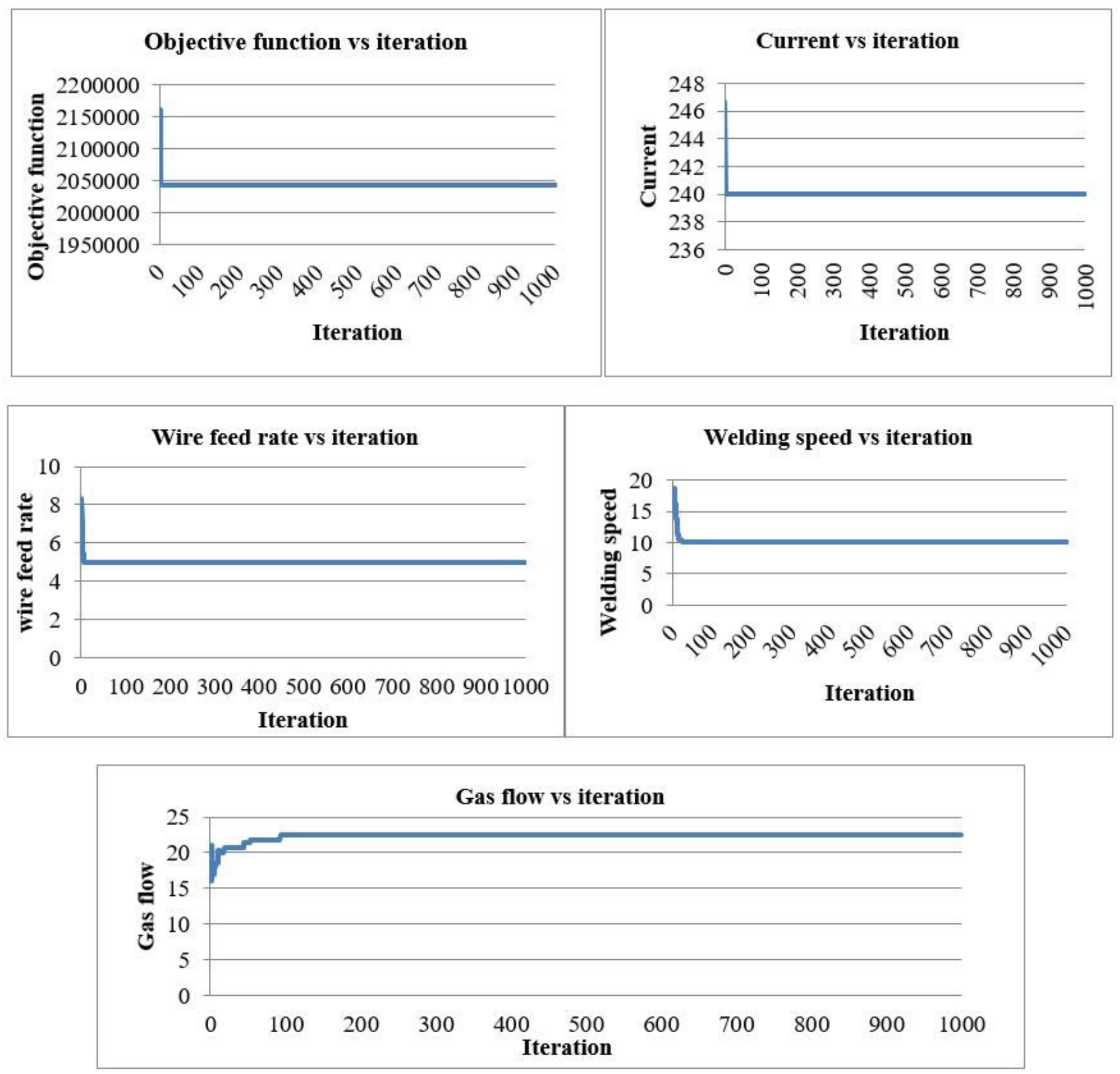

Figure 17

Convergence graph for welding input parameters using Firefly algorithm 

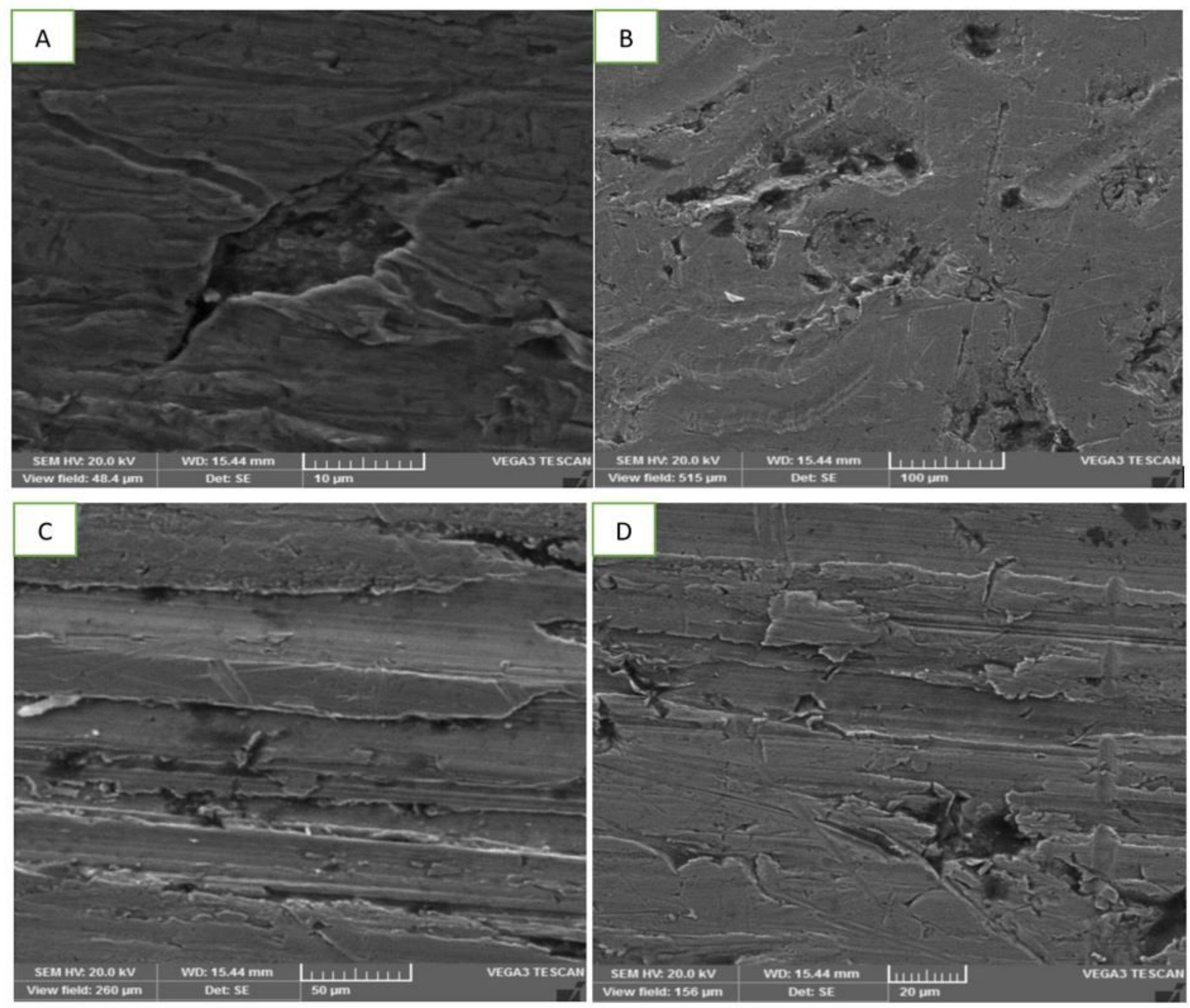

Figure 18

SEM observations of the tensile fractures of the welded joint 